\title{
ECN from Tussilago Farfara Attenuates Neuropathic Pain by Suppressing Oxidative Stress, Inflammatory and Pro-Apoptotic Proteins Expression in Surgical Model
}

\author{
Amna Khan ${ }^{1}$, Sidra Khalid ${ }^{1}$, Adnan Khan ${ }^{1}$, Bushra Shal' ${ }^{1}$ Eunwoo Kang ${ }^{2}$, Eun Kyoung Seo ${ }^{* * 2}$ and \\ Salman Khan*1 \\ 1 Department of Pharmacy, Faculty of Biological Sciences, Quaid-i-Azam University, Islamabad, Pakistan \\ 2 College of Pharmacy, Graduate School of Pharmaceutical Sciences, Ewha Womans University, Seoul 03760, \\ South Korea \\ * Correspondence:skhan@qau.edu.pk, Phone: +92-51-90644056; yuny@ewha.ac.kr. Phone: +82-2-3277-3047
}

Received: date; Accepted: date; Published: date

\begin{abstract}
Z-notonipetranone $(\mathrm{ECN}$ ), a sesquiterpenoid obtained from a natural origin (Tussilago farfara) has proved to be effective in minimizing various side effects associated with opioids and nonsteroidal anti-inflammatory drugs. The current study focused on investigating the effects of ECN on neuropathic pain induced by partial sciatic nerve ligation (PSNL) by mainly focusing on oxidative stress, inflammatory and apoptotic proteins expression in mice. Neuropathic pain was induced in mice by PSNL surgery performed on day 1 and ECN ( 1 and $10 \mathrm{mg} / \mathrm{kg}$, i.p.), was administered once daily for 11 days, starting from the third day after surgery. ECN post-treatment was found to reduce hyperalgesia and allodynia in a dose dependent manner. ECN significantly reversed the severity of neuropathic pain by improving distress symptoms and survival rate. ECN remarkably reversed the histopathological abnormalities associated with oxidative stress, apoptosis and inflammation. Furthermore, ECN prevented the suppression of antioxidants (glutathione, glutathione-Stransferase, catalase, superoxide dismutase, NF-E2-related factor-2 (Nrf2), hemeoxygenase-1 and $\mathrm{NAD}(\mathrm{P}) \mathrm{H}$ : quinone oxidoreductase) by PSNL. Moreover, pro-inflammatory cytokines (tumor necrotic factor alpha, interleukin 1 beta, interleukin 6, cyclooxygenase- 2 and inducible nitric oxide synthase) expression was reduced by ECN administration. Treatment with ECN was successful in reducing caspase-3 level consistent with the observed modulation of pro-apoptotic proteins. Additionally, ECN showed protective effect on the lipid content of myelin sheath as evident from FTIR spectroscopy which showed the shift of lipid component bands to higher values. Thus, antineuropathic potential of ECN might be due to inhibition of oxidative stress, inflammatory mediators and pro-apoptotic proteins.
\end{abstract}

Keywords: ECN; neuropathic pain; oxidative stress; apoptosis; myelin sheath; spectroscopy

\section{Introduction}

Neuropathic pain can result from the direct injury to various peripheral nerves via peripheral and central sensitization mechanisms as the pain stimuli are constantly produced which leads to impaired pain processing [1]. Neuropathic pain can arise from traumatic spinal cord injury, multiple sclerosis, stroke, persistent diabetes, lumbar disc syndrome, herpes infection, cancer and AIDS [2, 3]. Neuropathic pain is characterized by burning and stabbing pain due to hyperactivity of nerve fibres leading to hyperalgesia (increased pain sensitivity) and allodynia (pain resulting from non-painful stimuli) $[4,5]$. Different experimental models of neuropathic pain have been developed to assess the 
analgesic potentials of newer pharmacotherapies [6]. PSNL is the most commonly used model of peripheral neuropathy [7]. PSNL model produces unilateral peripheral mononeurotherapy as observed in humans that can be modelled for causalgia (incessant burning pain) and regional pain syndrome in rodents [8].

Oxidative stress and inflammation plays a key role in the initiation and maintenance of neuropathic pain [9]. Oxidative stress leads to the activation of reactive oxygen species which as a result amplifies the pathogenesis of neuropathic pain [10]. It has been reported that underlying cause of oxidative stress mediated neuropathic pain is the under-expression of Nrf2, a transcription factor involved in regulation of genes that encodes antioxidant proteins and phase 2 detoxifying enzymes [11]. Nrf2 binding with the antioxidant responsive element (ARE) leads to the transcriptional activation of downstream genes such as $\mathrm{NAD}(\mathrm{P}) \mathrm{H}$ : quinone oxidoreductase (NQO1), glutathione-Stransferase (GST) and hemeoxygenase-1 (HO-1) [11]. Moreover, several studies have shown that overexpression of Nrf2 produces protective effect against oxidative stress [9]. Recently, the activation of inflammatory markers and apoptotic pathways in the pathogenesis of neuropathic pain have been demonstrated [12]. Expression of inflammatory mediators such as tumor necrotic factor alpha (TNF$\alpha$ ), interleukin 1 beta (1L-1 $\beta$ ), interleukin 6 (1L-6), cyclooxygenase-2 (COX-2), inducible nitric oxide synthase (iNOS) while pro-apoptotic protein such as (caspase 3 ) contributes in the induction and maintenance of neuropathic pain [13, 14].

Phytochemicals have proved to be an effective Nrf2 activators inducing antioxidant proteins and phase 2 detoxifying enzymes [15]. Various studies have concluded that terpenoids possess neuroprotective effects [16]. A previous study revealed that a sesquiterpenoid, ECN isolated from Tussilago farfara exhibited remarkable neuroprotective activities [15]. The aim of present study was to assess the Nrf2 mediated anti-neuropathic activities of ECN against expression of oxidative stress proteins, inflammatory markers (COX-2, iNOS, TNF- $\alpha, 1 \mathrm{~L}-1 \beta, 1 \mathrm{~L}-6)$ and pro-apoptotic protein (caspase-3) in PSNL-induced neuropathic pain in mice.

\section{Results}

\subsection{Effect of ECN on distress symptoms and survival rate}

The highest mortality rate was observed in PSNL treated mice as compared to the normal control $(\mathrm{P}<0.05)$. The ECN treatment groups displayed higher survival rate as compared to the PSNL treated group $(\mathrm{P}<0.001)$ (Figure 1A). The PSNL treated group showed highest distress score as compared to the normal group $(\mathrm{P}<0.05)$. The ECN treatment groups displayed reduced distress scores as compared to the PSNL treated group $(\mathrm{P}<0.001)$ (Figure 1B). In brief, ECN groups showed reduced mortality rates and distress symptoms in comparison with PSNL treated group.
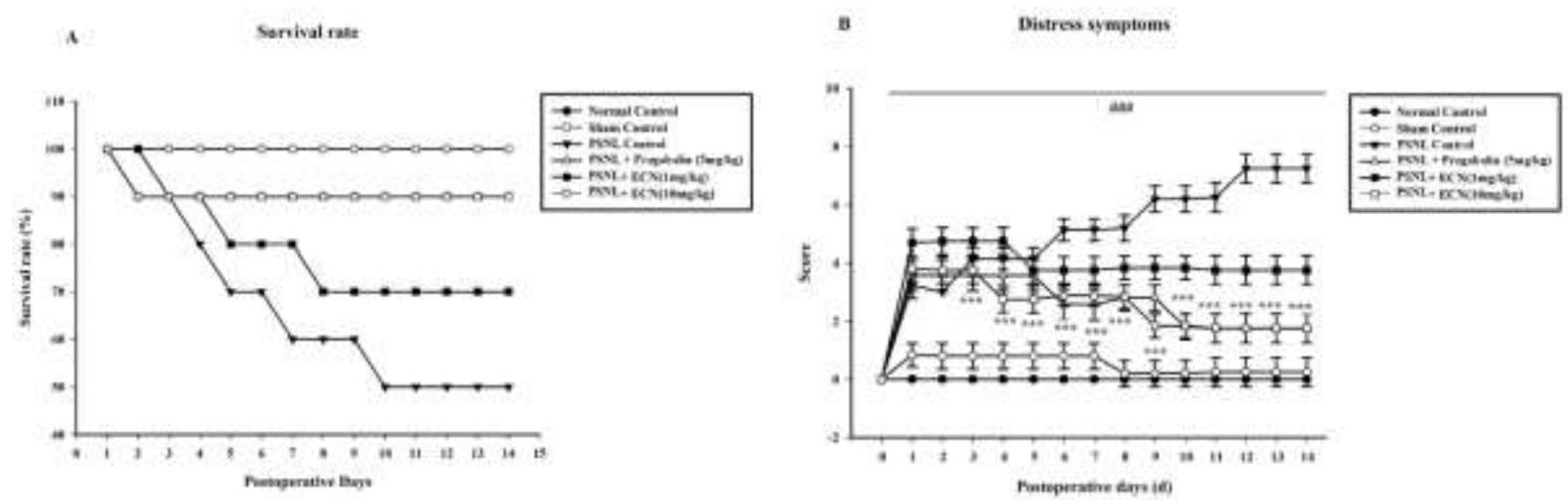

Figure 1. Effect of ECN treatment on survival rate and distress symptoms. (A) Survival rate during the experiment. Data is presented as percentage of number of mice survived each day. (B) Effect of ECN (1 and $10 \mathrm{mg} / \mathrm{kg}$ i.p.) treatment on distress symptoms. Total score of distress symptoms (dull/ruffled coat, change in temperament, reluctance to move) were recorded daily. Each criteria was scored from (0-3). Data shown is mean \pm S.D. from 5 mice. $\left({ }^{*}\right) \mathrm{P}<0.05,(* *) \mathrm{P}<0.01$, and $(* * *) \mathrm{P}<0.001$ 
indicates significant differences from the PSNL control group). (\#\#) means comparison of normal group and PSNL control group with treatment groups.

\subsection{Effect of ECN on neuropathic mechanical hyperalgesia, thermal hyperalgesia, mechanical allodynia and cold allodynia}

In PSNL-induced hyperalgesia, post-treatment with ECN (10 mg/kg) significantly inhibited mechanical hyperalgesia on day 3 in a dose dependent manner as compared to PSNL control (Figure 2A). Further evaluation of anti-inflammatory activity of drug was carried out by evaluating thermal hyperalgesia. Three days after injury, thermal hyperalgesia was significantly reduced in treatment groups as compared to PSNL-treated group. Post-treatment with ECN (10 mg/kg) significantly reduced the hyperalgesic responses such as paw licking and jumping (Figure 2B). Seven days after injury, thermal and mechanical hyperalgesia were still present in neuropathic mice, whereas ECN and positive control reversed the nociceptive hypersensitivity. In PSNL-induced mechanical allodynia, post-treatment with ECN $(10 \mathrm{mg} / \mathrm{kg})$ significantly reduced mechanical allodynia as compared to PSNL-treated group (Figure 2C). In PSNL-induced cold allodynia, post-treatment with ECN (10 mg/kg) inhibited cold allodynia as compared to PSNL-treated group (Figure 2D). In brief, ECN reduced the nociceptive hypersensitivity because of the neuropathic lesion in a time and dosedependent manner.
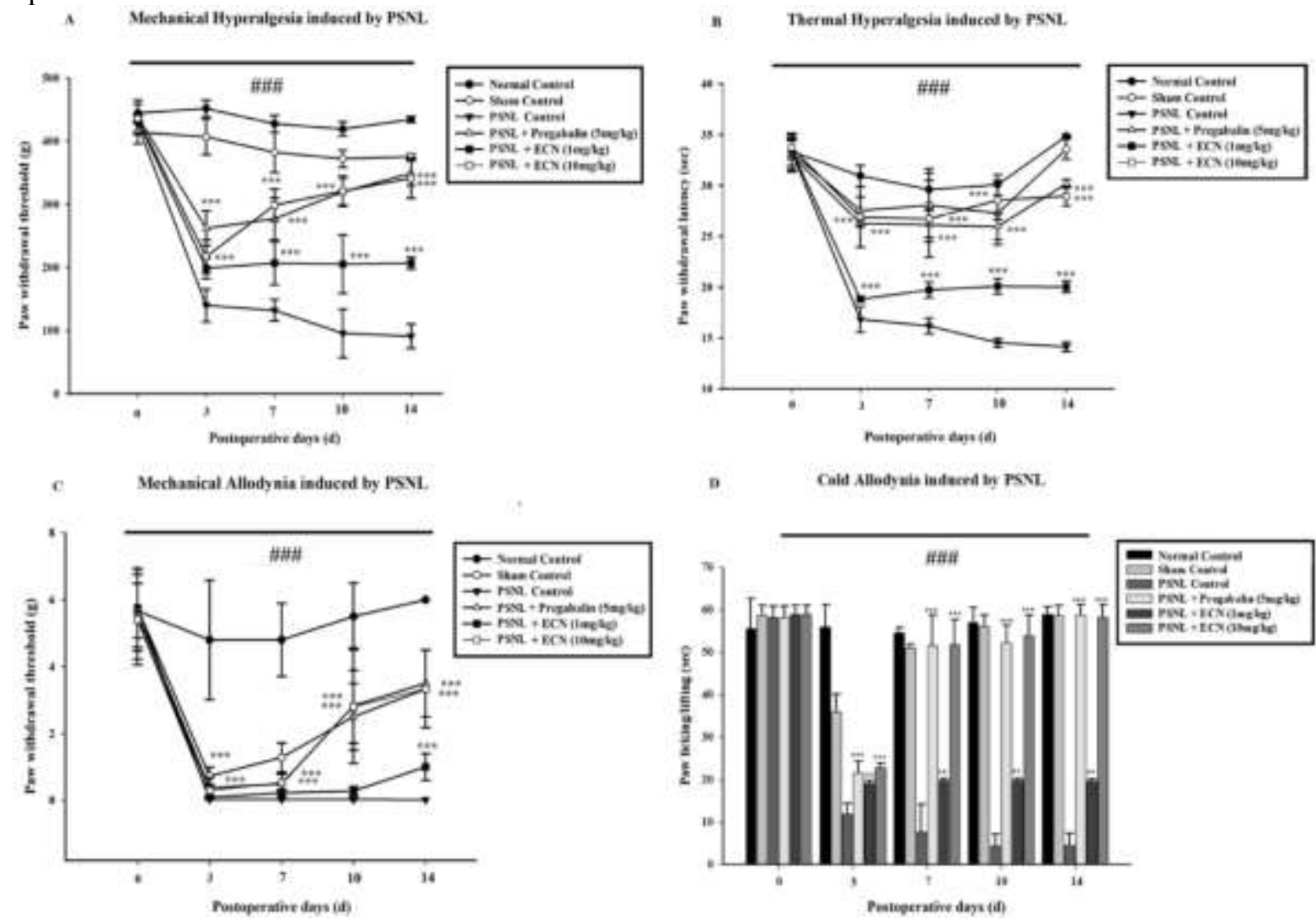

Figure 2. Effect of ECN treatment on mechanical hyperalgesia, thermal hyperalgesia, mechanical allodynia and cold allodynia. (A) Inhibition of PSNL-induced mechanical hyperalgesia at 0, 3, 7, 10 and 14 day intervals by ECN (1 and $10 \mathrm{mg} / \mathrm{kg}$ i.p.). (B) Inhibition of PSNL-induced thermal hyperalgesia at $0,3,7,10$ and 14 day intervals by ECN ( 1 and $10 \mathrm{mg} / \mathrm{kg}$ i.p). (C) Inhibition of PSNLinduced mechanical allodynia at $0,3,7,10$ and 14 day intervals by ECN (1 and $10 \mathrm{mg} / \mathrm{kg}$ i.p). (D) Inhibition of PSNL-induced cold allodynia at $0,3,7,10$ and 14 day intervals by ECN ( 1 and $10 \mathrm{mg} / \mathrm{kg}$ i.p). The data was reported as the means \pm S.D. $\left(^{*}\right) \mathrm{P}<0.05,\left({ }^{* *}\right) \mathrm{P}<0.01$ and $\left(^{* * *}\right) \mathrm{P}<0.001$ indicate significant differences from the PSNL control group. (\#\#) means comparison of normal group and PSNL control group with treatment groups. 


\subsection{Effect of ECN on neuropathic muscle and motor coordination}

Weight lifting and inverted screen tests showed that ECN-treated groups did not produced any abnormal effect on muscle and motor function. There was no noticeable deficit in muscle as well as motor coordination (Figure 3).
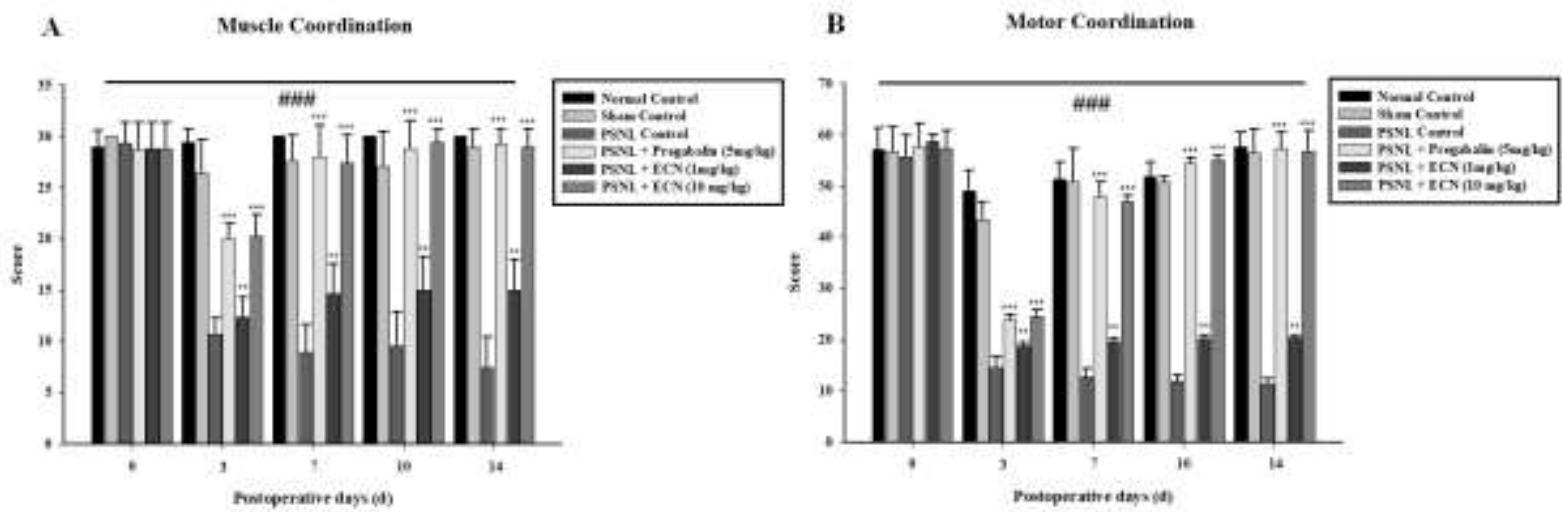

Figure 3. Effect of ECN (1 and $10 \mathrm{mg} / \mathrm{kg}$ i.p.) on PSNL-induced muscle activity by (A) Muscle coordination (B) Motor coordination. The effect on muscle coordination and motor coordination was measured at $0,3,7,10$ and 14 day after PSNL. The data were reported as the means S.D; ( $\mathrm{n}=5$ mice per group) of scoring average. The data was reported as the means \pm S.D. $\left({ }^{*}\right) \mathrm{P}<0.05,\left({ }^{* *}\right) \mathrm{P}<0.01$ and $\left({ }^{* *}\right) \mathrm{P}<0.001$ indicate significant differences from the PSNL control group. (\#\#\#) means comparison of normal group and PSNL control group with treatment groups.

\subsection{Effect of ECN on DNA disruption}

PSNL control group showed augmentation of DNA damage in sciatic nerve and spinal cord tissue. Administration of ECN $(10 \mathrm{mg} / \mathrm{kg})$ significantly $(\mathrm{P}<0.001)$ reduced DNA damage with a decrease in tail length and percentage DNA in tail as compared to the PSNL challenged group (Figure 4).

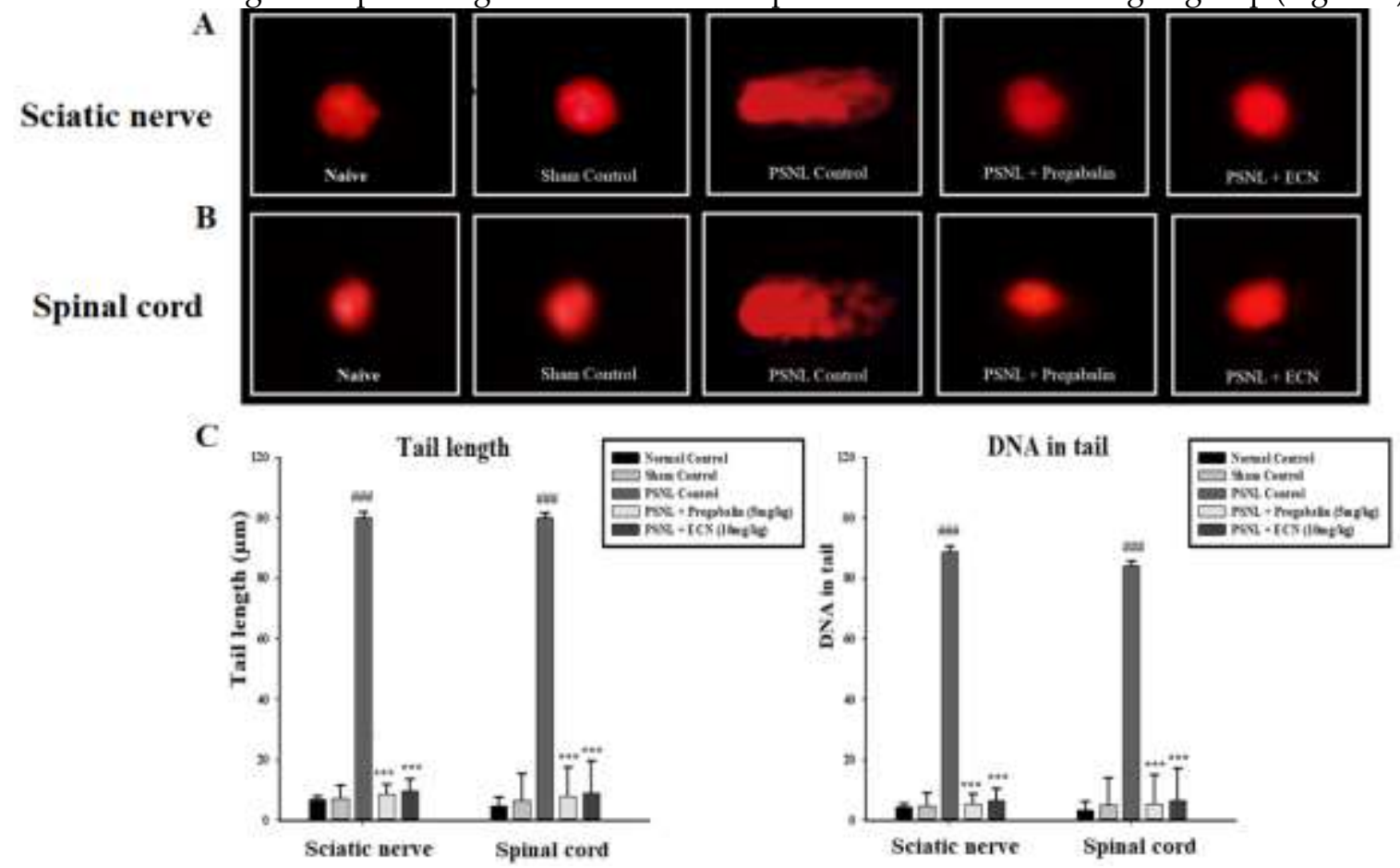

Figure 4. Effect of ECN on DNA damage in sciatic nerve and spinal cord tissues analysed by comet assay. Fluorescence photomicrographs exhibiting protective effect of ECN against PSNL induced DNA damage in (A) sciatic nerve and (B) spinal cord. (C) DNA content is estimated by tail length and $\%$ DNA in tail in PSNL experiment. The data is presented as the mean $(n=5) \pm S . D .{ }^{*} P<0.05,{ }^{* *} P<0.01$ 
and ${ }^{* * *} P<0.001$ represents a statistically significant variation from PSNL-induced group. (\#\#\#) denotes comparison of normal control group and PSNL-induced group with ECN treated group. .

\subsection{Effect of ECN on histological examination}

H\&E staining analysis of the sciatic nerve section showed that ECN $(10 \mathrm{mg} / \mathrm{kg})$ reduced the swelling of nerve fiber, degenerated myelin sheath, hypertrophy of satellite cells and necrosis at day 7 and 14 post PSNL surgery when observed under light microscope (Figure 5). ECN treated groups showed reduction in myelin swelling, cell infiltration and necrosis of lumbar spinal cord section at day 7 and 14 post PSNL surgery in contrast to PSNL control when observed under light microscope (Figure 6). Histopathological analysis of the coronal section of brain showed significant $(\mathrm{P}<0.001)$ increase in thickness of dentate gyrus in treatment groups when quantified by Image J tool (Figure 7).

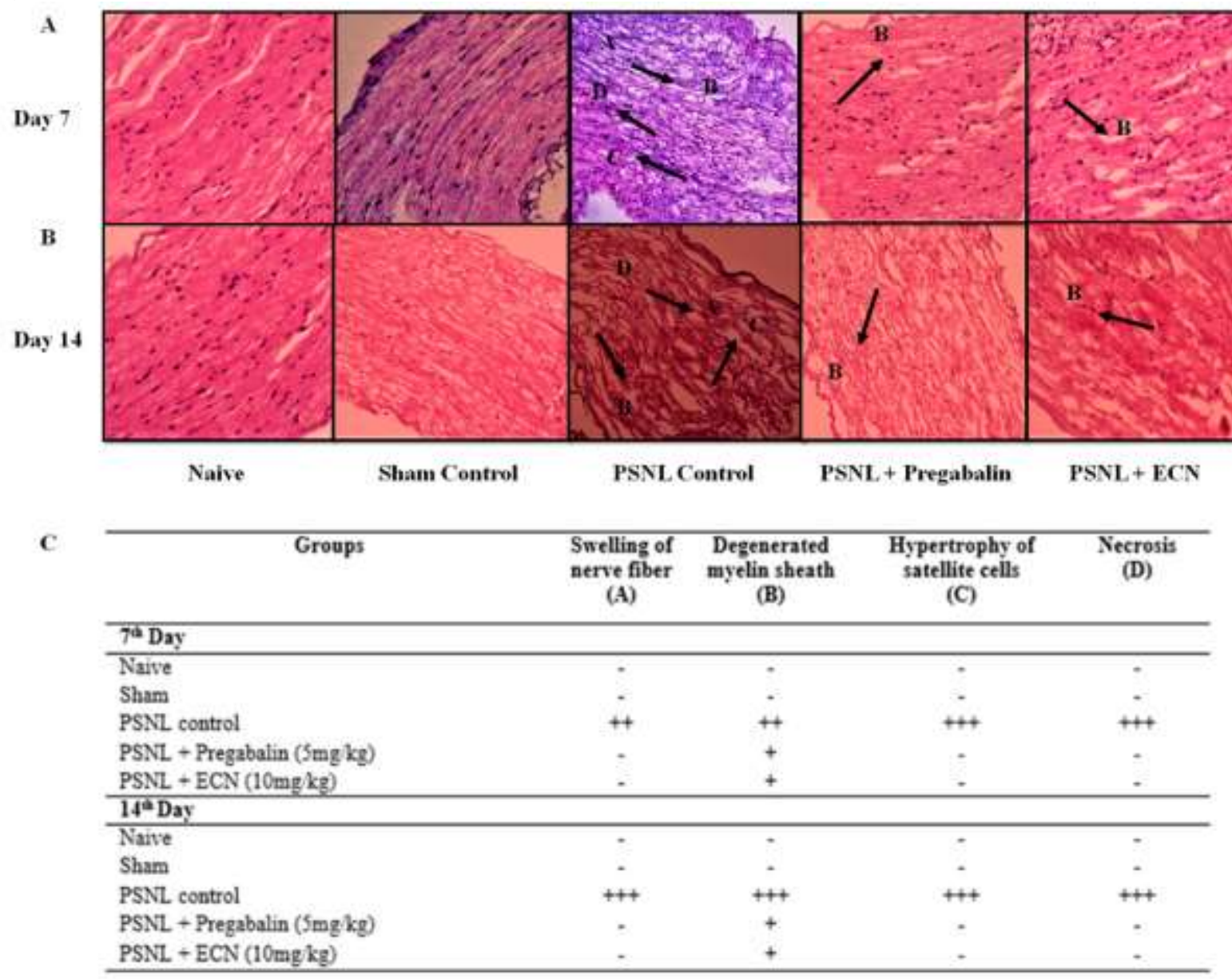

Figure 5. Effect of ECN $(10 \mathrm{mg} / \mathrm{kg})$ on the pathological histology of sciatic nerve tissue. The sciatic nerve of mice subjected to PSNL is shown in longitudinal sections stained with hematoxylin and eosin at 100X magnification. (A) Pathological histology of sciatic nerve tissue on day 7 post PSNL surgery. (B) Pathological histology of sciatic nerve tissue on day 14 post PSNL surgery. (C) Table illustrating swelling of nerve fiber, degenerated myelin sheath, hypertrophy of satellite cells and necrosis on 7 and 14 day post PSNL surgery. The data was reported as the means \pm S.D. $\left({ }^{*}\right) \mathrm{P}<0.05,\left({ }^{* *}\right) \mathrm{P}<0.01$ and $\left.{ }^{* * *}\right) \mathrm{P}<0.001$ indicate significant differences from the PSNL control group. (\#\#\#) means comparison of naïve group and PSNL control group with treatment groups. 


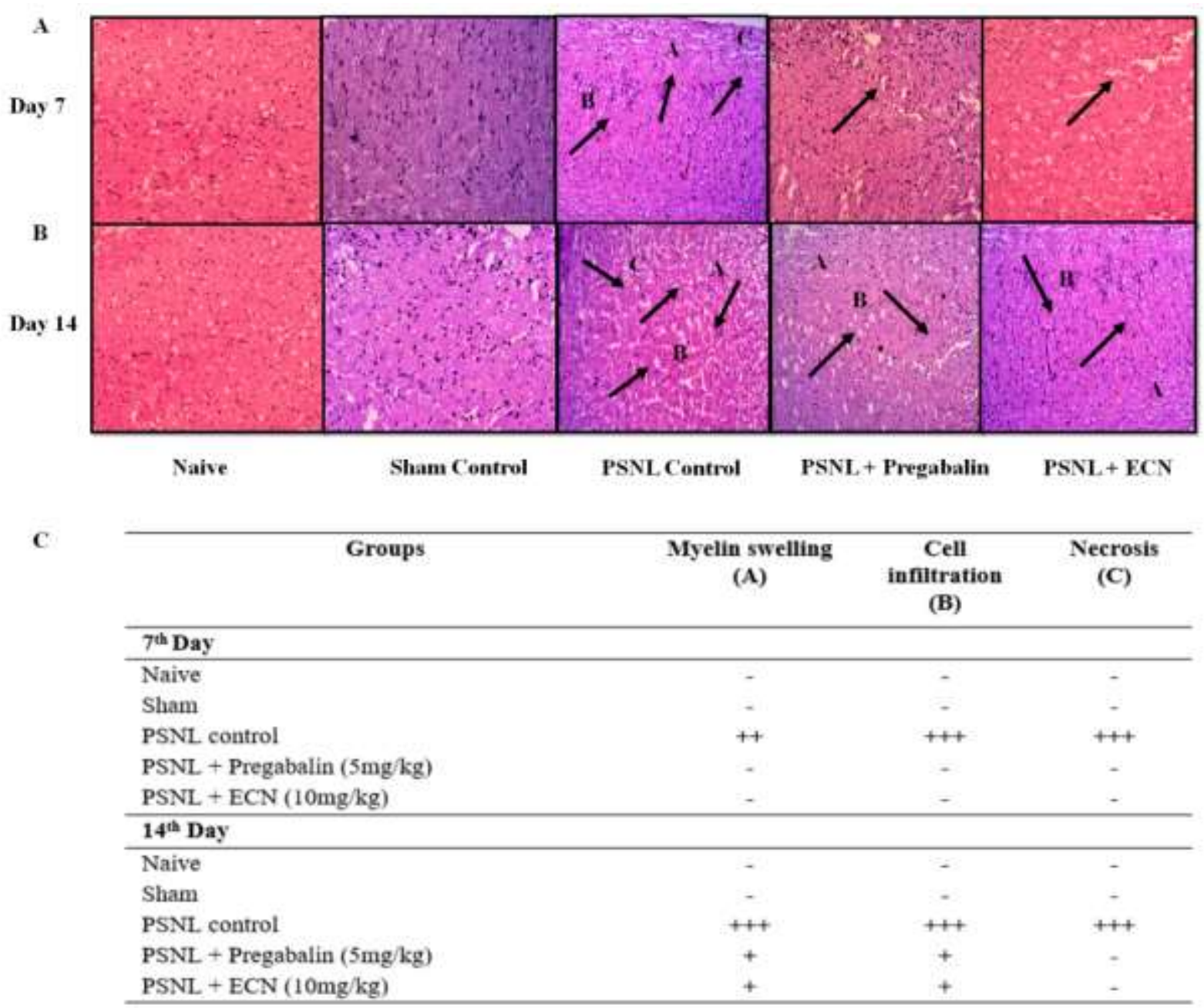

Figure 6. Effect of ECN $(10 \mathrm{mg} / \mathrm{kg})$ on the pathological histology of lumbar spinal cord tissue, the lumbar spinal cord of mice subjected to PSNL is shown in transverse sections stained with hematoxylin and eosin at 100X magnification. (A) Pathological histology of lumbar spinal cord tissue on day 7 post PSNL surgery. (B) Pathological histology of lumbar spinal cord tissue on day 14 post PSNL surgery. (C) Table illustrating myelin swelling, cell infiltration and necrosis on 7 and 14 day post PSNL surgery. The data was reported as the means \pm S.D. $\left({ }^{*}\right) \mathrm{P}<0.05,\left({ }^{* *}\right) \mathrm{P}<0.01$ and $\left({ }^{* *}\right) \mathrm{P}<$ 0.001 indicate significant differences from the PSNL control group. (\#\#) means comparison of naive group and PSNL control group with treatment groups. 


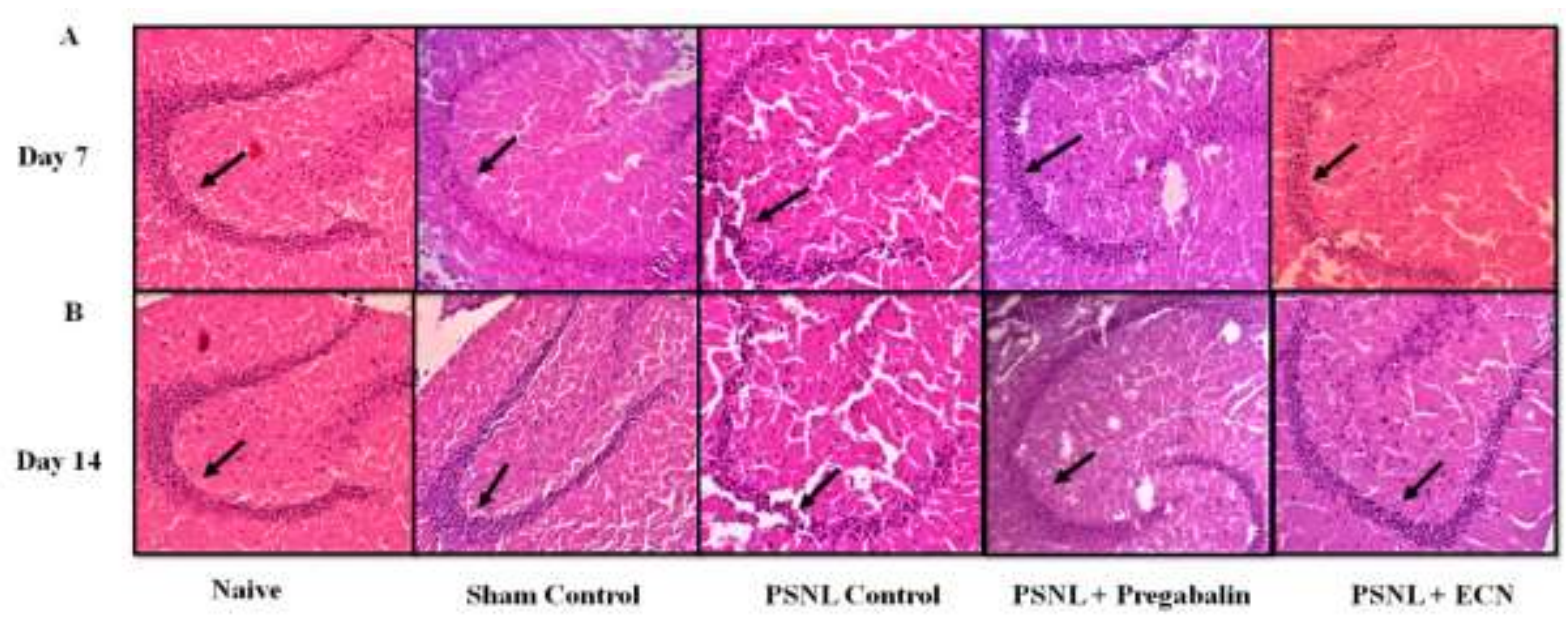

C

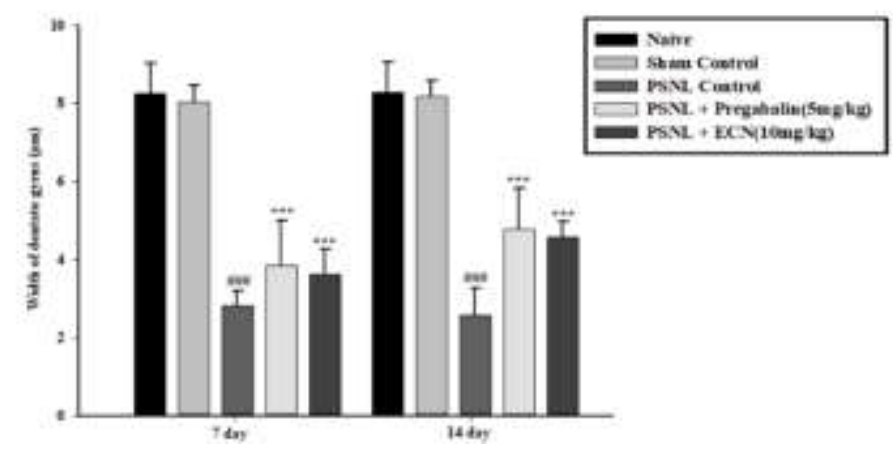

Figure 7. Effect of ECN (10 mg/kg) on the pathological histology of brain tissue, the dentate gyrus of mice subjected to PSNL is shown in coronal sections stained with hematoxylin and eosin at 100X magnification. (A) Pathological histology of brain tissue on day 7 post PSNL surgery. (B) Pathological histology of brain tissue on day 14 post PSNL surgery. (C) Thickness of dentate gyrus in micrometer $(\mu \mathrm{m})$ on 7 and 14 day post PSNL surgery. The data was reported as the means \pm S.D. $\left({ }^{*}\right) \mathrm{P}<0.05,\left({ }^{* *}\right)$ $\mathrm{P}<0.01$ and $\left(^{* * *}\right) \mathrm{P}<0.001$ indicate significant differences from the PSNL control group. (\#\#\#) means comparison of naive group and PSNL control group with treatment groups.

\subsection{Effect of ECN on inflammatory cytokines expression}

The effect of ECN (10 mg/kg) was also investigated against various pro-inflammatory cytokines such as TNF $\alpha$, IL-1 $\beta$, IL-6, COX-2 and iNOS in the spinal cord and sciatic nerve tissues using quantitative RT-PCR. Neuropathic pain strongly induced expression of TNF- $\alpha$, IL-1 $\beta$, IL-6, COX-2 and iNOS, the treatment with ECN significantly $(\mathrm{P}<0.001)$ decreased the mRNA expression levels of these inflammatory cytokines as compared to the PSNL-treated group (Figure 8). 

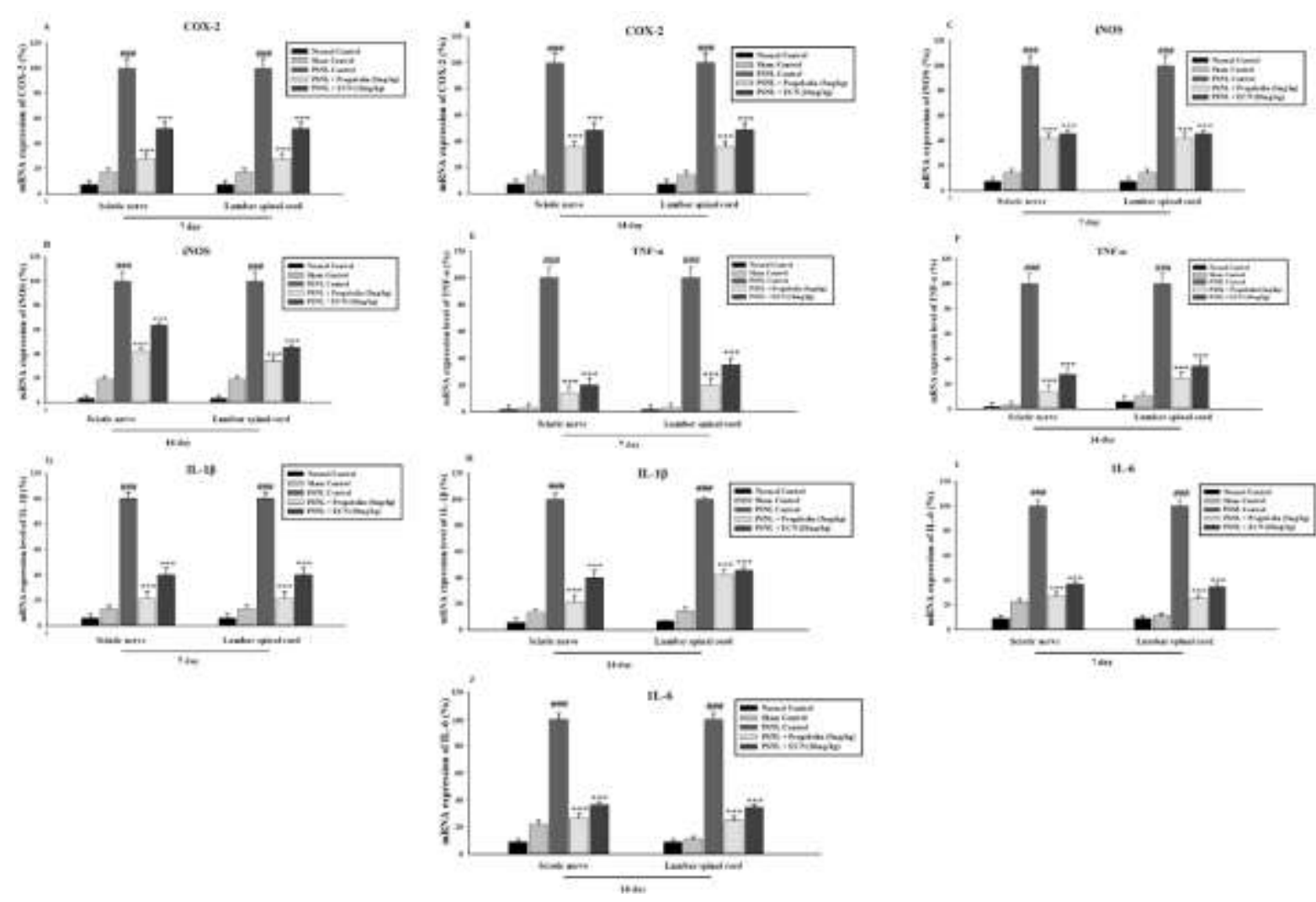

Figure 8. Effect of ECN (10 mg/kg) on the COX-2, iNOS, TNF $\alpha$, IL- $1 \beta$ and IL-6 expression in spinal cord and sciatic nerve tissue using PCR. (A) ECN (10 mg/kg) significantly inhibited the COX-2 in sciatic nerve and spinal cord tissue on day 7 post PSNL surgery. (B) ECN (10 mg/kg) significantly inhibited the COX-2 in sciatic nerve and spinal cord tissue on day 14 post PSNL surgery. (C) ECN (10 $\mathrm{mg} / \mathrm{kg}$ ) significantly inhibited the iNOS in sciatic nerve and spinal cord tissue on day 7 post PSNL surgery. (D) ECN $(10 \mathrm{mg} / \mathrm{kg})$ significantly inhibited the iNOS in sciatic nerve and spinal cord tissue on day 14 post PSNL surgery. (E) ECN (10 mg/kg) significantly inhibited the TNF- $\alpha$ in sciatic nerve and spinal cord tissue on day 7 post PSNL surgery. (F) ECN (10 mg/kg) significantly inhibited the TNF- $\alpha$ in sciatic nerve and spinal cord tissue on day 14 post PSNL surgery. (G) ECN (10 mg/kg) significantly inhibited the IL-1 $\beta$ in sciatic nerve and spinal cord tissue on day 7 post PSNL surgery. (H) ECN $(10 \mathrm{mg} / \mathrm{kg})$ significantly inhibited the IL-1 $\beta$ in sciatic nerve and spinal cord tissue on day 14 post PSNL surgery. (I) ECN (10 mg/kg) significantly inhibited the IL-6 in sciatic nerve and spinal cord tissue on day 7 post PSNL surgery. (J) ECN $(10 \mathrm{mg} / \mathrm{kg})$ significantly inhibited the IL-6 in sciatic nerve and spinal cord tissue on day 14 post PSNL surgery. The data was reported as the means \pm S.D. $\left(^{*}\right) P$ $<0.05,\left({ }^{* *}\right) \mathrm{P}<0.01$ and $\left(^{* *}\right) \mathrm{P}<0.001$ indicate significant differences from the PSNL control group. (\#\#) means comparison of naive group and PSNL control group with treatment groups.

\subsection{Effect of ECN on anti-oxidants expression}

The mRNA expression levels of anti-oxidant enzymes and proteins such as Nrf2, HO-1 and NQO1 in spinal cord and sciatic nerve of mice were determined using quantitative RT-PCR. Oxidative stress leads to the activation of reactive oxygen species which as a result amplifies the pathogenesis of neuropathic pain. The present results showed that there was a significant $(\mathrm{P}<0.001)$ up-regulation of Nrf2, HO-1 and NQO1 enzyme due to ECN and pregabalin treatment as compared to the PSNL-treated group (Figure 9). 

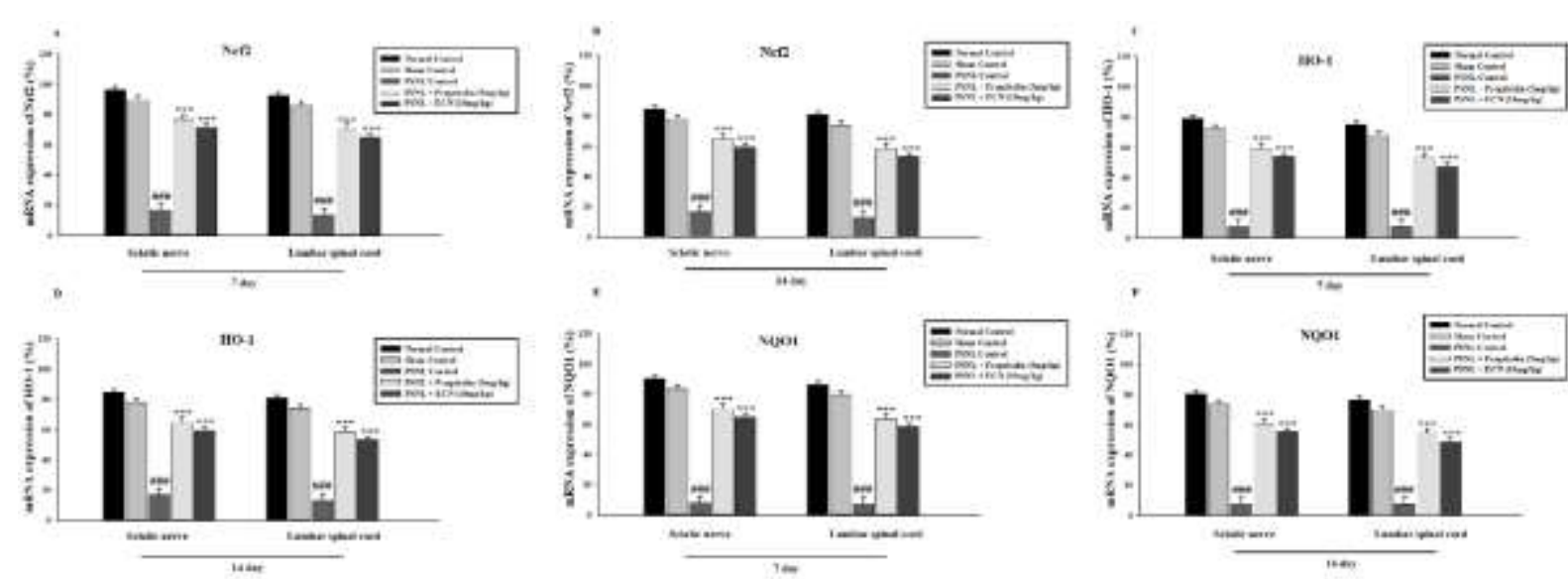

Figure 9. Effects of $\mathrm{ECN}(10 \mathrm{mg} / \mathrm{kg}$, i.p.) on the oxidative stress markers in spinal cord and sciatic nerve tissue using qtRT-PCR. (A) ECN (10 mg/kg, i.p) treatment significantly enhanced the mRNA expression levels of Nrf2 in sciatic nerve and spinal cord tissue on day 7 post PSNL surgery. (B) ECN $(10 \mathrm{mg} / \mathrm{kg}$, i.p) treatment significantly enhanced the mRNA expression levels of Nrf2 in sciatic nerve and spinal cord tissue on day 14 post PSNL surgery. (C) ECN $(10 \mathrm{mg} / \mathrm{kg}$, i.p) treatment significantly enhanced the mRNA expression levels of HO-1 in sciatic nerve and spinal cord tissue on day 7 post PSNL surgery. (D) ECN (10 mg/kg, i.p) treatment significantly enhanced the mRNA expression levels of HO-1 in sciatic nerve and spinal cord tissue on day 14 post PSNL surgery. (E) ECN (10 mg/kg, i.p) treatment significantly enhanced the mRNA expression levels of NQO1 in sciatic nerve and spinal cord tissue on day 7 post PSNL surgery. (F) ECN (10 mg/kg, i.p) treatment significantly enhanced the mRNA expression levels of NQO1 in sciatic nerve and spinal cord tissue on day 14 post PSNL surgery. The data was reported as the means \pm S.D. $\left({ }^{*}\right) \mathrm{P}<0.05,(* *) \mathrm{P}<0.01$ and $\left({ }^{* *}\right) \mathrm{P}<0.001$ indicate significant differences from the PSNL control group. (\#\#) means comparison of naive group and PSNL control group with treatment groups.

\subsection{Effect of ECN on MDA production.}

The MDA level in sciatic nerve, spinal cord and brain (prefrontal cortex and hippocampus) was determined on 7, 10 and 14 day after PSNL surgery. Upregulation of oxidative stress markers after nerve injury plays a major role in promoting pathogenesis of neuropathic pain. Treatment with ECN and pregabalin significantly $(\mathrm{P}<0.001)$ decreased the MDA level as compared to PSNL control group (Figure 10). 

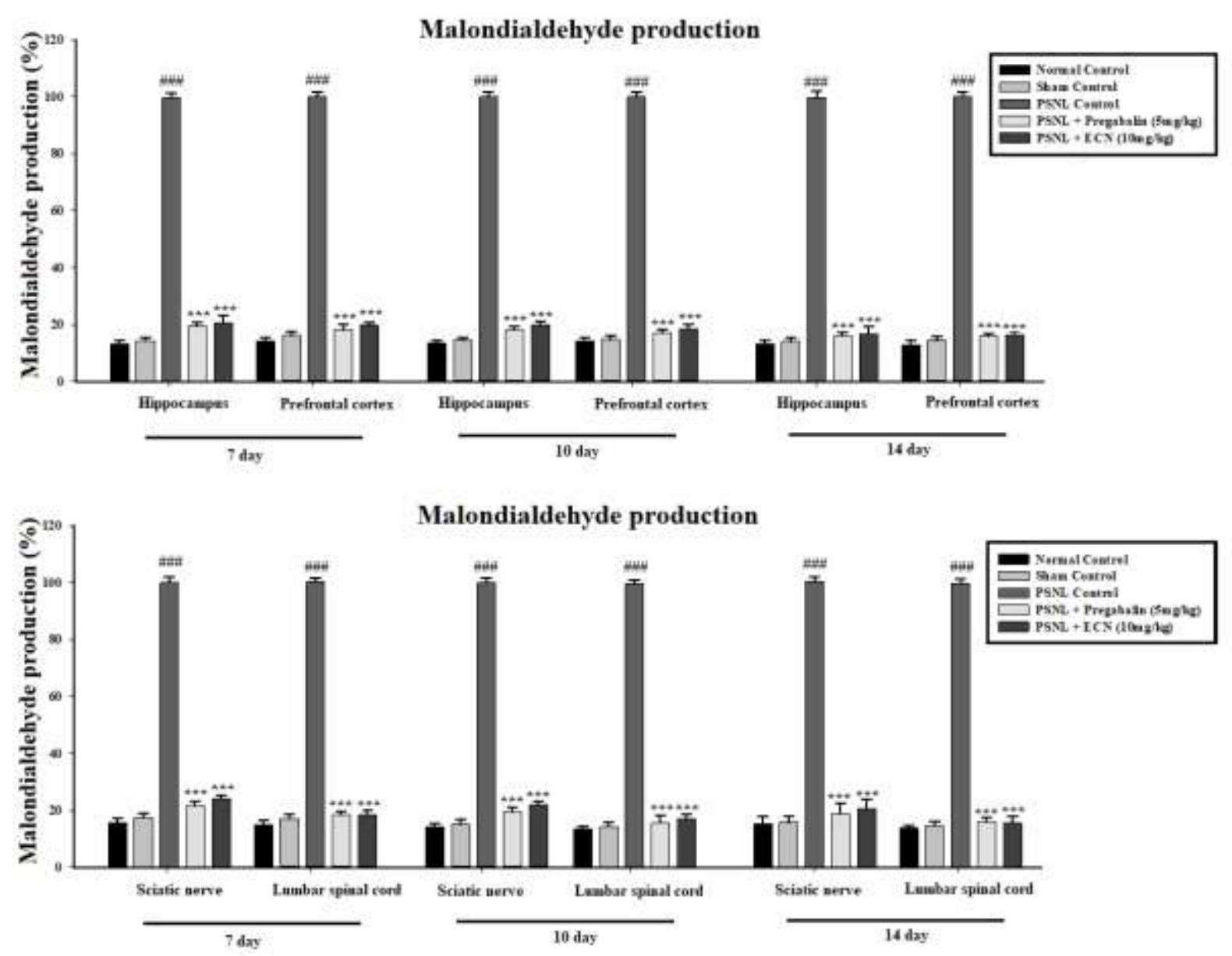

Figure 10. Effect of $\mathrm{ECN}(10 \mathrm{mg} / \mathrm{kg})$ on MDA level on 7,10 and 14 day post PSNL surgery in hippocampus, prefrontal cortex, sciatic nerve and lumbar spinal cord of mice. MDA level expressed as percentage. The data was reported as the means \pm S.D. $\left({ }^{*}\right) \mathrm{P}<0.05,\left({ }^{* *}\right) \mathrm{P}<0.01$ and $\left(^{* * *}\right) \mathrm{P}<0.001$ indicate significant differences from the PSNL control group. (\#\#) means comparison of normal group and PSNL control group with treatment groups.

\subsection{Effect of ECN on NO production}

Nitrite level was determined in brain (hippocampus, prefrontal cortex), spinal cord and sciatic nerve tissue on 7, 10 and 14 day post PSNL surgery (Figure 11). Excess reactive oxygen species leads to the increased production of NO which further worsens the neuropathic pain. Treatment with ECN significantly $(\mathrm{P}<0.001)$ reduced the PSNL induced nitrite production, hence this confirmed the antiinflammatory effect of drug. 

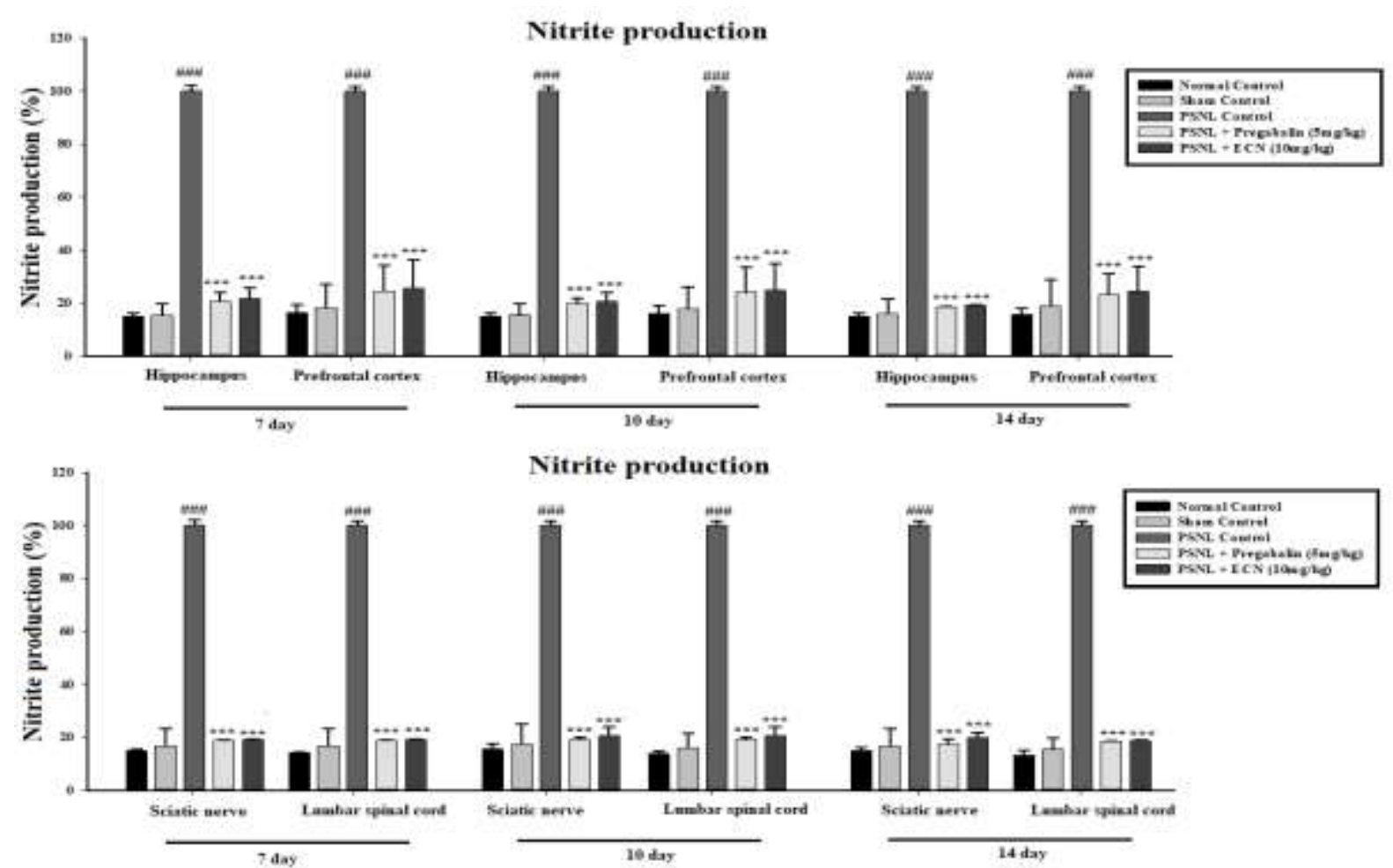

Figure 11. Effect of ECN (10 mg/kg) on NO production on 7, 10 and 14 day post PSNL surgery in hippocampus, prefrontal cortex, sciatic nerve and lumbar spinal cord of mice. NO level expressed as percentage. The data was reported as the means \pm S.D. $\left(^{*}\right) \mathrm{P}<0.05,\left({ }^{*}\right) \mathrm{P}<0.01$ and $\left({ }^{* *}\right) \mathrm{P}<0.001$ indicate significant differences from the PSNL control group. (\#\#) means comparison of normal group and PSNL control group with treatment groups.

\subsection{Effect of ECN on SOD}

SOD level was determined in brain (hippocampus, prefrontal cortex), spinal cord and sciatic nerve tissue on 7, 10 and 14 day post PSNL surgery (Figure 12). Increased expression of antioxidant proteins and enzymes can treat the neuropathic pain induced by oxidative stress. Treatment with ECN and pregabalin significantly $(\mathrm{P}<0.001)$ increased the level of SOD antioxidant enzyme, therefore this confirmed the antioxidant effect of ECN. 

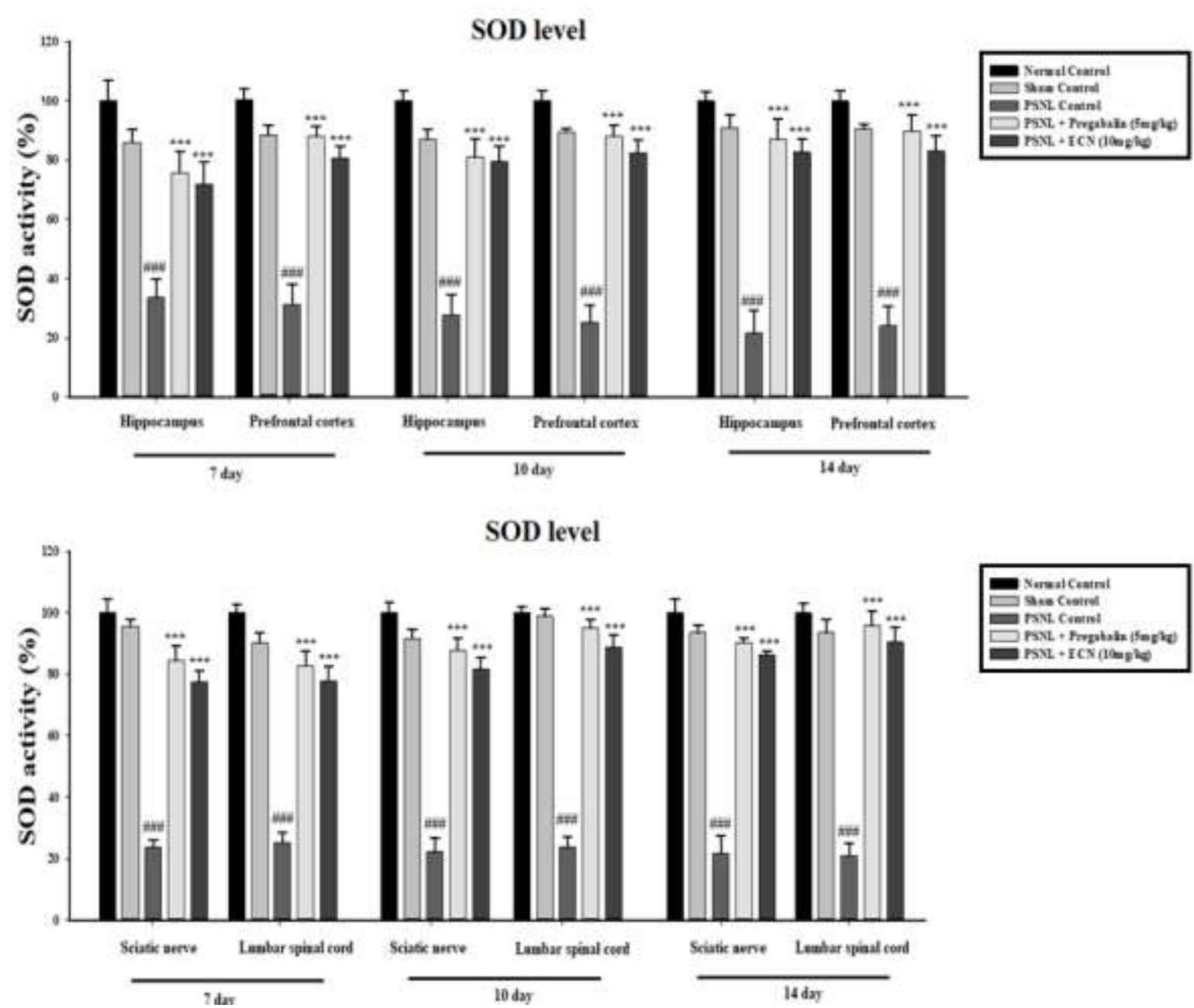

Figure 12. Effect of ECN $(10 \mathrm{mg} / \mathrm{kg})$ on reduced SOD level on 7,10 and 14 day post PSNL surgery in hippocampus, prefrontal cortex, sciatic nerve and lumbar spinal cord of mice. SOD level expressed as percentage. The data was reported as the means \pm S.D. $\left(^{*}\right) \mathrm{P}<0.05,\left({ }^{* *}\right) \mathrm{P}<0.01$ and $\left({ }^{* * *}\right) \mathrm{P}<0.001$ indicate significant differences from the PSNL control group. (\#\#) means comparison of normal group and PSNL control group with treatment groups.

\subsection{Effect of ECN on GSH}

GSH level was determined in hippocampus, prefrontal cortex, lumbar spinal and sciatic nerve on 7, 10 and 14 day post PSNL surgery (Figure 13). Upregulation of antioxidant proteins and enzymes can treat the neuropathic pain induced by oxidative stress. Treatment with ECN and positive control significantly $(\mathrm{P}<0.001)$ increased the level of GSH antioxidant protein as compared to the PSNL control group. 

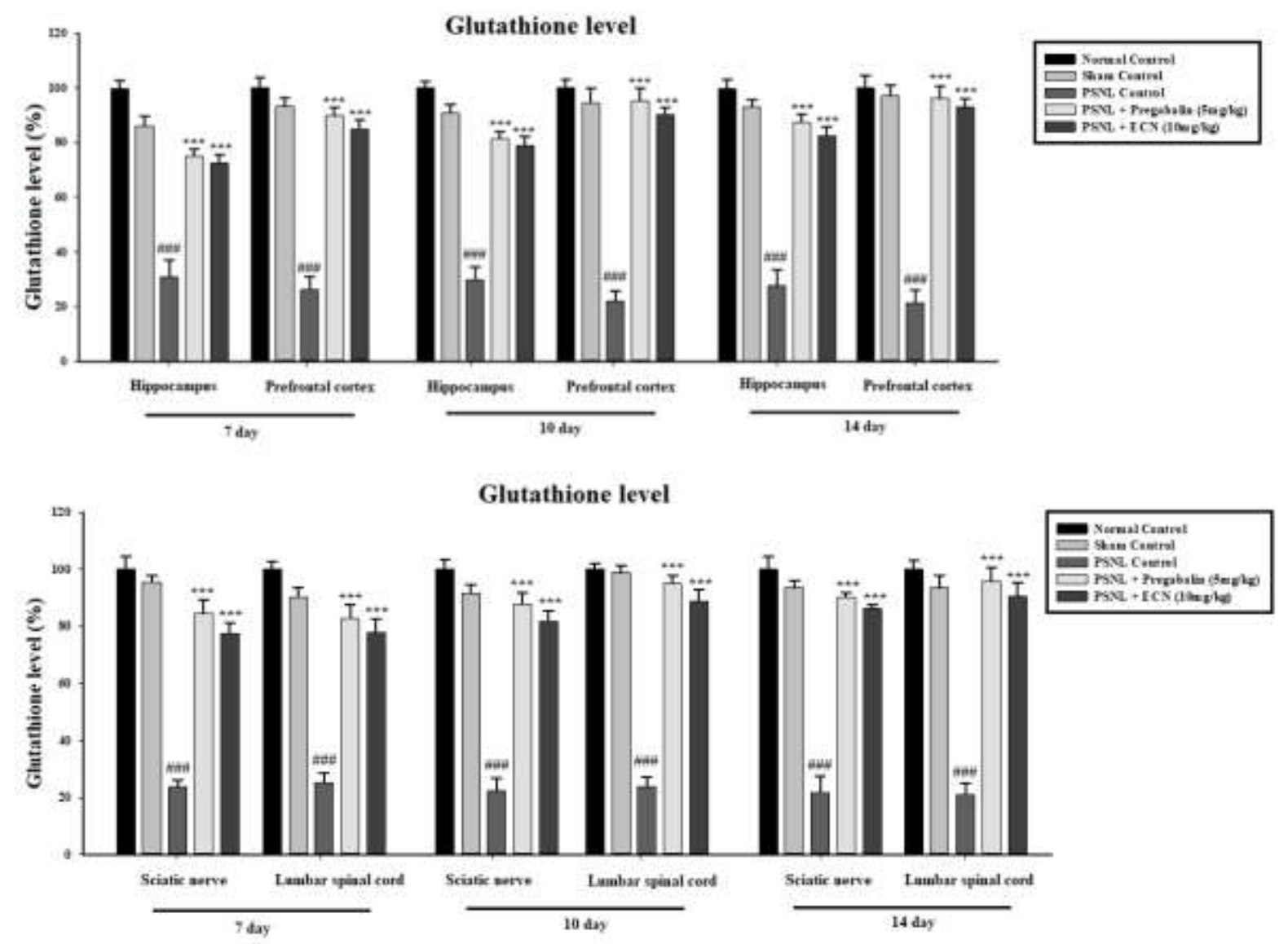

Figure 13. Effect of ECN (10 mg/kg) on GSH level on 7, 10 and 14 day post PSNL surgery in hippocampus, prefrontal cortex, sciatic nerve and lumbar spinal cord of mice. GSH level expressed as percentage. The data was reported as the means \pm S.D. $\left({ }^{*}\right) \mathrm{P}<0.05,\left({ }^{* *}\right) \mathrm{P}<0.01$ and $\left(^{* * *}\right) \mathrm{P}<0.001$ indicate significant differences from the PSNL control group. (\#\#\#) means comparison of normal group and PSNL control group with treatment groups.

\subsection{Effect of ECN on GST.}

The GST level in sciatic nerve, spinal cord and brain (prefrontal cortex and hippocampus) was determined on 7, 10 and 14 day after PSNL surgery (Figure 14). Neuropathic pain cause significant increase in free radicals which as a result amplifies the pathogenesis of neuropathic pain. Treatment with ECN and pregabalin significantly $(\mathrm{P}<0.001)$ increased the level of GST antioxidant enzyme as compared to the PSNL control group. 

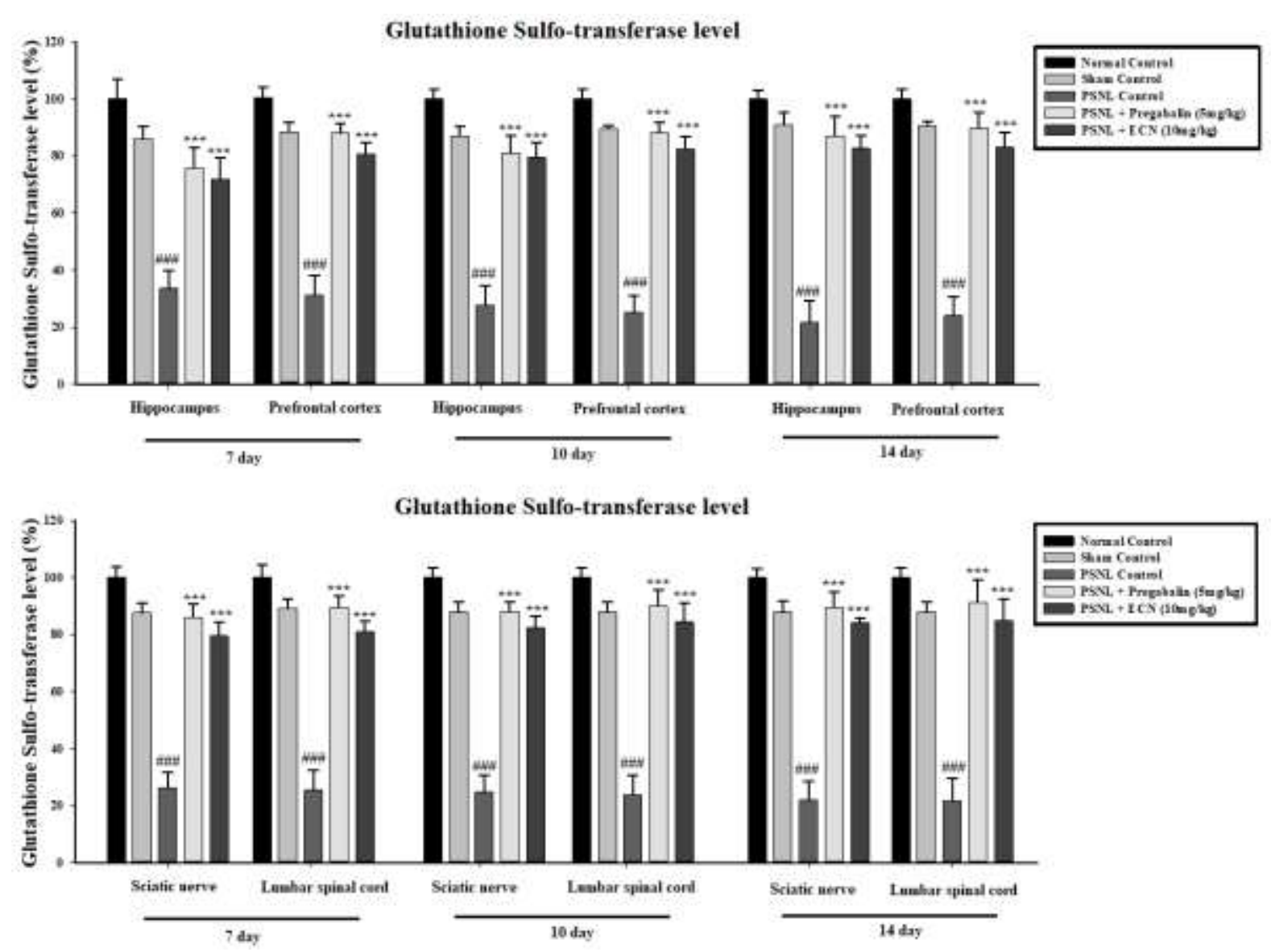

Figure 14. Effect of ECN (10 mg/kg) on GST level on 7, 10 and 14 day post PSNL surgery in hippocampus, prefrontal cortex, sciatic nerve and lumbar spinal cord of mice. GST level expressed as percentage. The data was reported as the means \pm S.D. $\left(^{*}\right) \mathrm{P}<0.05,\left({ }^{* *}\right) \mathrm{P}<0.01$ and $\left({ }^{* * *}\right) \mathrm{P}<0.001$ indicate significant differences from the PSNL control group. (\#\#) means comparison of normal group and PSNL control group with treatment groups.

\subsection{Effect of ECN on Catalase.}

The catalase level in brain (prefrontal cortex and hippocampus), spinal cord and sciatic nerve was determined on 7, 10 and 14 day after PSNL surgery (Figure 15). Increased expression of antioxidant proteins and enzymes can treat the neuropathic pain induced by oxidative stress. Treatment with ECN and pregabalin significantly $(\mathrm{P}<0.001)$ increased the level of catalase as compared to the PSNL control group. 

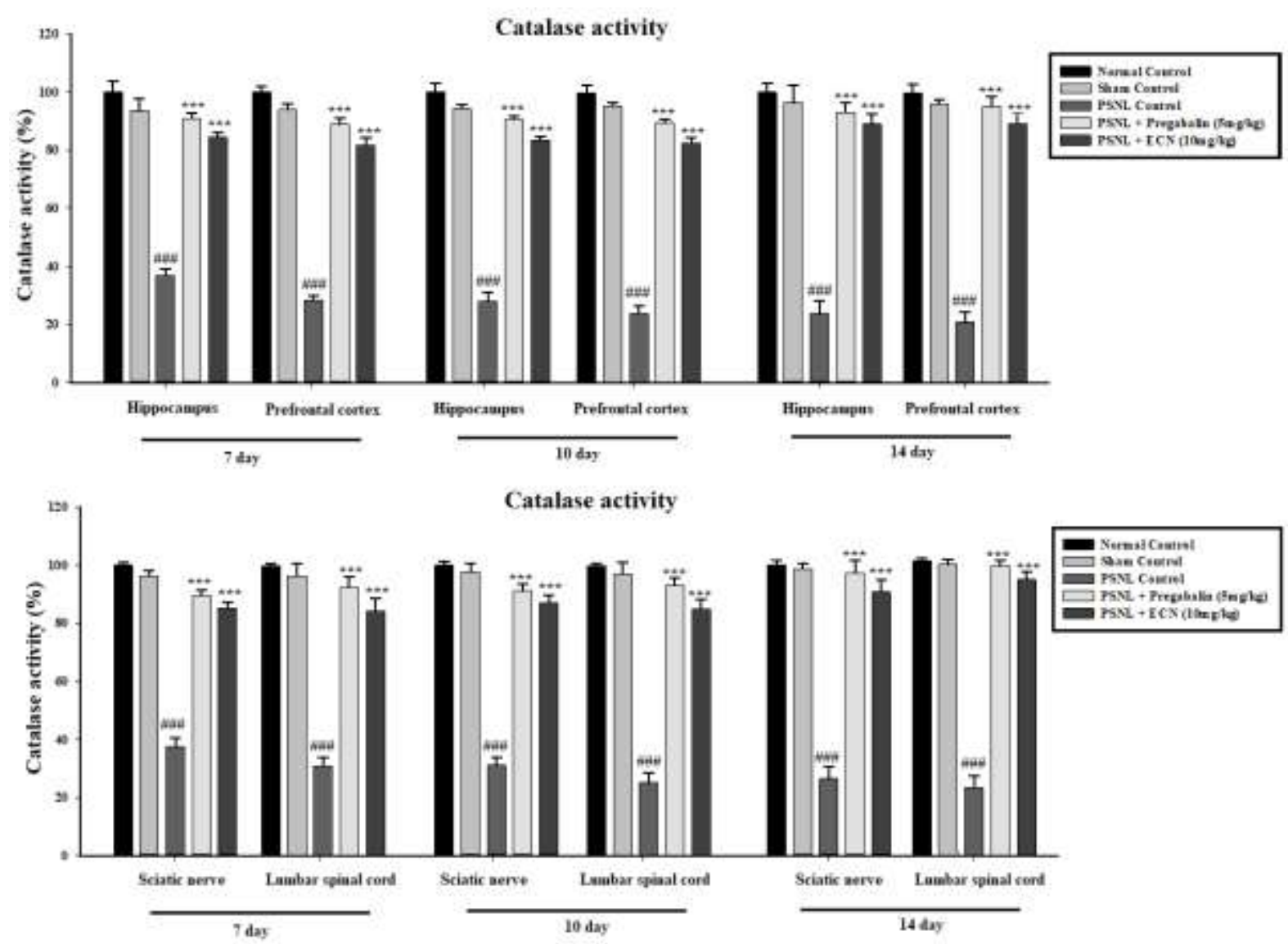

Figure 15. Effect of ECN (10 mg/kg) on catalase level on 7, 10 and 14 day post PSNL surgery in hippocampus, prefrontal cortex, sciatic nerve and lumbar spinal cord of mice. Catalase level expressed as percentage. The data was reported as the means \pm S.D. $\left({ }^{*}\right) \mathrm{P}<0.05,\left({ }^{* *}\right) \mathrm{P}<0.01$ and $\left(^{* * *}\right)$ $\mathrm{P}<0.001$ indicate significant differences from the PSNL control group. (\#\#\#) means comparison of normal group and PSNL control group with treatment groups.

\subsection{Effect of ECN on Kidney and Liver Functions}

The side effect profile of drug on liver and kidney was evaluated through measurement of AST, ALT and creatinine concentrations in blood plasma. Daily treatment with ECN starting from day 3 did not changed plasma levels of AST and ALT and creatinine as compared to the PSNL control (Table 1).

Table 1. Effect of ECN on liver and kidney functions in PSNL experiment.

\begin{tabular}{cccc}
\hline Parameters & ALT (IU/L) & AST (IU/L) & Creatinine (mg/dl) \\
\hline Naive & $23.33 \pm 0.67$ & $20.33 \pm 0.87$ & $1.02 \pm 1.83$ \\
PSNL Control & $60.33^{\mathrm{a}} \pm 1.82$ & $48.66^{\mathrm{a}} \pm 3.31$ & $2.32^{\mathrm{a}} \pm 4.14$ \\
ECN (10mg/kg) & $29.5^{\mathrm{b}} \pm 4.65$ & $25.5^{\mathrm{b}} \pm 2.24$ & $1.10^{\mathrm{b}} \pm 0.27$ \\
\hline
\end{tabular}

Values are expressed as the mean S.D ( $\mathrm{n}=5$ mice/ group); ${ }^{\mathrm{P}} \mathrm{P} 0.001$ compared with the naive group; $\mathrm{b}$ 0.001 compared with the PSNL control group.

\subsection{Effect of ECN on Nrf2 and caspase-3 expression}

Modulatory action of ECN was further strengthened by assessing the expressions of caspase-3 and Nrf2 by using immunohistochemistry. Caspase-3, a pro-apoptotic protein plays a vital role in the pathogenesis of neuropathic pain. The present result showed that ECN post treatment significantly $(\mathrm{P}<0.001)$ decreased the immune-labelling of caspase-3 as compared to the PSNL control (Figure 16A and 16C). The underlying cause of oxidative stress mediated neuropathic pain is the under- 
expression of Nrf2, a transcription factor involved in regulation of genes that encodes antioxidant proteins and phase 2 detoxifying enzymes. ECN post treatment significantly $(\mathrm{P}<0.001)$ upregulated the expression of Nrf2 as compared to the PSNL control when observed under light microscope (Figure 16B and $16 \mathrm{C}$ ).
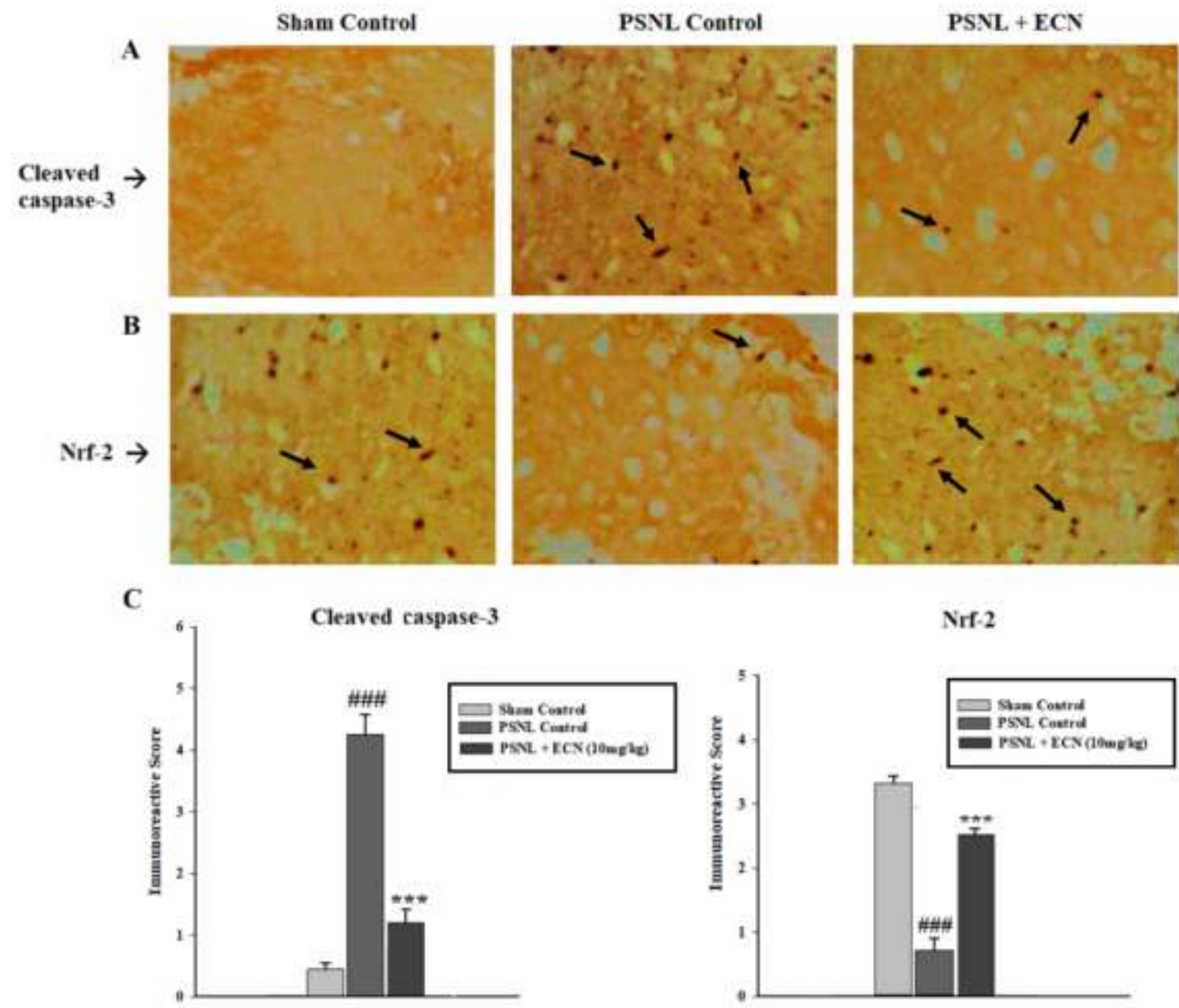

Figure 16. Effect of ECN (10 mg/kg, i.p) on the immunohistochemical staining of mice spinal cord, showing the effect of ECN on PSNL induced expression of caspase-3 (A) and Nrf2 (B). ECN treatment reduced the expression of caspase- 3 and enhanced the expression of $\mathrm{Nrf} 2(\mathrm{C})$. The data was reported as the means \pm S.D. $\left.\left(^{*}\right) \mathrm{P}<0.05,{ }^{* *}\right) \mathrm{P}<0.01$ and $\left(^{* *}\right) \mathrm{P}<0.001$ indicate significant differences from the PSNL control group. (\#\#\#) means comparison of naive group and PSNL control group with treatment groups.

\subsection{Effect of ECN on myelin sheath of sciatic nerve}

ECN exhibited protective effect on the lipid content of myelin sheath which shows its potential to treat nerve damage or neuropathy (Figure 17). The change in unsaturated fatty acid lipid content is determined from the analysis of the olefinic band, arisen from $\mathrm{HC}=\mathrm{CH}$ groups [17]. The wavenumber of this band was shifted significantly $(\mathrm{P}<0.001)$ to higher value in the ECN treated group as compared to the PSNL control group (Table 2). The $\mathrm{CH}_{2}$ antisymmetric $\left(2927 \mathrm{~cm}^{-1}\right)$, and the $\mathrm{CH}_{2}$ symmetric $\left(2857 \mathrm{~cm}^{-1}\right)$ stretching bands originates mainly from lipids. The $\mathrm{CH}_{3}$ antisymmetric $\left(2959 \mathrm{~cm}^{-1}\right)$ has equal contribution from lipids and proteins (Table 3) [18-21]. The wavenumber of these bands in ECN group was shifted significantly $(\mathrm{P}<0.001)$ to higher value as compared to the PSNL control group (Table 2). 


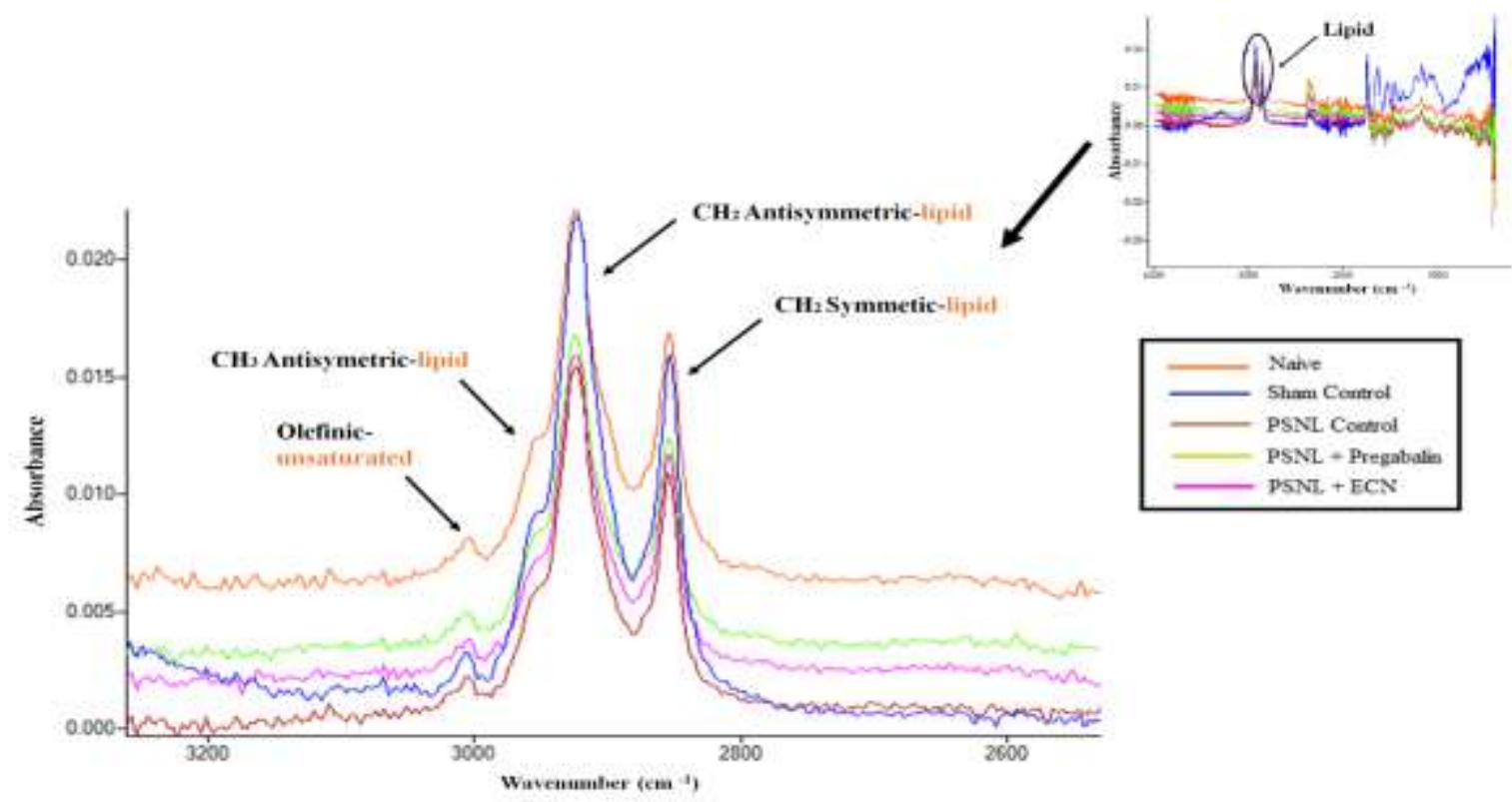

Figure 17. Effects of ECN (10 mg/kg) on lipid content of sciatic nerve. The FTIR spectra of the naive, sham control, PSNL control, PSNL + pregabalin and PSNL + ECN treated sciatic nerve in the range of $3025-2800 \mathrm{~cm}^{-1}$.

Table 2. The changes in the band wavenumber values of sciatic nerve spectra in the range of 3025$2800 \mathrm{~cm}^{-1}$.

\begin{tabular}{|c|c|c|c|c|c|c|}
\hline Bands & Naive & $\begin{array}{c}\text { Sham } \\
\text { Control }\end{array}$ & $\begin{array}{c}\text { PSNL } \\
\text { Control }\end{array}$ & $\begin{array}{c}\text { PSNL + } \\
\text { Pregabalin }\end{array}$ & $\begin{array}{c}\text { PSNL + } \\
\text { ECN }\end{array}$ & $\mathbf{P}$ \\
\hline Olefinic & $\begin{array}{c}3008.9 \pm \\
0.04\end{array}$ & $\begin{array}{c}3004.2 \pm \\
1.96\end{array}$ & $\begin{array}{c}2999.3 \pm \\
0.57\end{array}$ & $3003.2 \pm 0.39$ & $\begin{array}{c}3002.2 \pm \\
0.39\end{array}$ & $* * *$ \\
\hline $\begin{array}{c}\mathrm{CH}_{2} \\
\text { antisymmetric }\end{array}$ & $\begin{array}{c}2926.9 \pm \\
1.59\end{array}$ & $\begin{array}{c}2924.5 \pm \\
2.11\end{array}$ & $\begin{array}{c}2918.0 \pm \\
0.90\end{array}$ & $2921.2 \pm 0.35$ & $\begin{array}{c}2920.3 \pm \\
0.34\end{array}$ & $* * *$ \\
\hline $\mathrm{CH}_{2}$ symmetric & $\begin{array}{c}2857.23 \pm \\
1.14\end{array}$ & $\begin{array}{c}2854.6 \pm \\
2.46\end{array}$ & $\begin{array}{c}2848.0 \pm \\
0.88\end{array}$ & $2853.3 \pm 0.4$ & $\begin{array}{c}2852.1 \pm \\
0.26\end{array}$ & $* * *$ \\
\hline $\begin{array}{c}\mathrm{CH}_{3} \\
\text { antisymmetric }\end{array}$ & $\begin{array}{c}2958.7 \pm \\
0.13\end{array}$ & $\begin{array}{c}2955.6 \pm \\
3.14\end{array}$ & $\begin{array}{c}2851.2 \pm \\
1.07\end{array}$ & $2950.4 \pm 0.51$ & $\begin{array}{c}2948.1 \pm \\
1.01\end{array}$ & $* * *$ \\
\hline
\end{tabular}

Table 3. General Band Assignment table for Sciatic nerve (Garip and Severcan 2010; Ozek et al., 2010).

\begin{tabular}{|c|c|}
\hline $\begin{array}{l}\text { Wavenumber }\left(\mathrm{cm}^{-}\right. \\
\text {1) }\end{array}$ & Definition of the spectral assignment \\
\hline 3014 & $\begin{array}{c}\text { Olefinic }=\mathrm{CH} \text { stretching vibration: unsaturated lipids, cholesterol } \\
\text { esters. }\end{array}$ \\
\hline 2962 & $\begin{array}{c}\mathrm{CH}_{3} \text { antisymmetric stretching: equal contribution of lipids, and } \\
\text { proteins, carbohydrates, nucleic acids. }\end{array}$ \\
\hline 2929 & $\begin{array}{l}\mathrm{CH}_{2} \text { antisymmetric stretching: mainly lipids, with the little } \\
\text { contribution from proteins, carbohydrates, nucleic acids }\end{array}$ \\
\hline 2855 & $\begin{array}{l}\mathrm{CH}_{2} \text { symmetric stretching: mainly lipids, with the little contribution } \\
\text { from proteins, carbohydrates, nucleic acids }\end{array}$ \\
\hline
\end{tabular}




\section{Discussion}

Chronic pain initiated by a primary lesion or dysfunction in the nervous system and leads to prolonged changes in pain pathway structures (neuroplasticity) and abnormal processing of sensory information [22]. Chronic pain is a big challenge to the healthcare scientist [23]. PSNL model produces unilateral peripheral mononeurotherapy as observed in humans that can be modelled for causalgia (incessant burning pain) and regional pain syndrome in rodents. Numerous drugs are already in the market for the treatment of neuropathic pain $[22,24]$. The drugs for the treatment of neuropathic pain exhibited severe and serious side effects [22]. Therefore, there is a need to seek out new drugs with more safety and more efficacious profile.

In the present study an attempt was made to explore the potential effects of naturally isolated ECN in PSNL-induced model of neuropathic pain. PSNL model has been used clinically for the treatment of neuropathic pain [25]. Intraperitoneal administration of ECN $(10 \mathrm{mg} / \mathrm{kg})$ post-treatment once daily starting from day 3 after surgery, significantly attenuated mechanical hyperalgesia, thermal hyperalgesia, mechanical allodynia and cold allodynia. Decreased score of distress symptoms such as general health, changes in temperament, gait weakness and reluctance to move were observed in the treatment group as compared to the PSNL control group. High survival rate were seen in the treatment group as compared to the PSNL control group. In addition ECN (10 $\mathrm{mg} / \mathrm{kg}$ ) intraperitoneal administration from day 3 after surgery reversed histopathological abnormalities of PSNL-induced neuropathic pain. Our findings suggest that ECN had no disturbing effect on the muscle coordination and motor activity.

Earlier studies have reported the activation of pro-inflammatory cytokines and apoptotic markers in the induction and maintenance of neuropathic pain [26, 27]. Upregulation of inflammation and apoptotic proteins after injury plays a crucial role in aggravating the neuropathic pain [28, 29]. Previous findings reported that the up-regulation of inflammatory and apoptotic markers after nerve injury plays a major role in promoting pathogenesis of neuropathic pain [16, 30]. In pathological conditions, excess reactive oxygen species and apoptosis leads to the increased production of proinflammatory cytokines which further worsens the neuropathic pain [31]. In the present study we found that pro-inflammatory (TNF- $\alpha$, IL-1 $\beta$ and IL-6) and pro-apoptotic (caspase-3) proteins were elevated in the spinal cord and sciatic nerve of mice on day 7 and 14 after PSNL surgery. Treatment with ECN decreased the TNF- $\alpha$, IL-1 $\beta$, IL- 6 and caspase 3 expression in contrast to PSNL group.

Recent findings suggests that iNOS releases NO and subsequently peroxynitrite which could lead to the production of pro-inflammatory cytokines and could participate in neuropathic pain [32]. Moreover, it has been demonstrated that increased production of iNOS and TNF- $\alpha$ could be responsible for the development of neuropathic pain [30]. In pathological conditions, large amounts of pro-inflammatory cytokines such as iNOS and TNF- $\alpha$ are released which further causes the production of reactive oxygen species (ROS) [12]. In the current study, ECN showed antiinflammatory effect by inhibiting the expression of iNOS and TNF- $\alpha$.

$\mathrm{Nrf2}$, one of the basic leucine zipper transcription factor that can bind to ARE-sequence has been shown to be important for protection against oxidative stress [33]. Many chronic neurological disorders such as multiple sclerosis and neuropathic pain are thought to involve oxidative stress as a factor contributing to the progression of disease [34]. Earlier studies reported that activation of Nrf2 pathway might be a contributing factor for the treatment of neuropathic pain [9]. It has been found that Nrf2 gene expression is vital for the maintenance and responsiveness of cell's defence system [12]. In the current study, we found that increased Nrf2 gene expression can treat the neuropathic pain induced by oxidative stress. Treatment with ECN increased the expression of Nrf2 and its downstream proteins such as HO-1 and NQO1 in treatment groups as compared to the PSNL group.

Previous studies have found that activation of apoptosis might be involved in the pathogenesis of neuropathic pain [12]. Apoptotic pathways leads to the activation of caspase-3 which leads to cell death [35]. Caspase-3, a pro-apoptotic protein plays a vital role in the pathogenesis of neuropathic pain [36]. Moreover it has been demonstrated that inhibition of caspase 3 would inhibit apoptosis and thermal hyperalgesia following chronic constriction injury [37]. In this study, caspase-3 
expression in the treatment group was reduced as compared to the PSNL control group. This shows the protective effect of ECN in neuropathic pain.

Quantitative DNA damage in sciatic and spinal cord tissues were analysed with the help of comet assay. DNA disruption was identified by DNA relocation out of the nucleus and into the tail of comet. DNA strand breakage can be due to the enhanced generation of ROS leading to free radical formation which might be the reason for the alteration and breakage of double helical strands causing cell death [38]. This DNA disruption was noticeably attenuated by ECN representing its neuroprotective potential. Moreover, coronal section of the brain tissue, longitudinal section of the sciatic nerve and transverse section of the lumbar spinal cord were stained with H\&E and then observed under microscope. It was found that dentate gyrus of hippocampus in PSNL-challenged group was reduced in thickness as compared to the treatment group. In the same way increased signs inflammation was observed in PSNL-induced sciatic nerve and lumbar spinal cord demonstrating debilitating condition of PSNL control group. Although, such pattern was not seen in treatment group. This shows the efficient potential of ECN in treating peripheral neuropathy.

To elucidate the lipid content of myelin sheath of sciatic nerve in PSNL model, FTIR spectroscopy was used in this study since it enables efficient, rapid and simultaneous monitoring of small changes in biochemical components and processes in diseases or drug-induced pathological conditions $[17,20]$. Damage to myelin sheath via alteration in the biochemical make-up of the sciatic nerve tissue contributes to neuropathy. ECN exhibited protective effect on the lipid content of myelin sheath which shows its potential to treat nerve damage or neuropathy. The change in unsaturated fatty acid lipid content is determined from the analysis of the olefinic band, arisen from $\mathrm{HC}=\mathrm{CH}$ groups. In the current study, the wavenumber of this band was shifted significantly to higher value in ECN treated groups as compared to the PSNL control group.

\section{Materials and Methods}

\subsection{Plant material}

ECN was isolated from dried buds of T. farfara (mentioned compound was received from Prof. Yeong Shik Kim, Seoul National University, South Korea) and identified by comparison with spectral data $\left({ }^{1} \mathrm{H}\right.$ NMR and $\left.{ }^{13} \mathrm{C} \mathrm{NMR}\right)$, as previously reported in the literature [39]. The extraction and purification of ECN was reported by our team elsewhere [39].

\subsection{Chemicals and reagents}

Pregabalin was purchased from Sigma-Aldrich, Germany. Ketamine (Ketarol, 500 mg/10ml) was purchased from Global Pharmaceutical, Islamabad, Pakistan. Pyodine was purchased from Brookes Pharma, Karachi, Pakistan. All the other chemicals used in the current study were of analytical grade. All the drugs described above were freshly prepared for the study, dissolved in $2 \%$ DMSO and diluted with $0.9 \%$ saline.

\subsection{Animals and surgical procedure}

Male albino mice (3-4 weeks of age) having weight of 25-30 g were purchased from National Institute of Health (NIH), Islamabad, Pakistan. Animals were housed in a controlled laboratory environment at a temperature of $23 \pm$ $1{ }^{\circ} \mathrm{C}$ in $50 \pm 10 \%$ humidity under a $12 \mathrm{~h}$ light-dark cycle. Standard lab chow and water were provided throughout the experiment. All the experiments were performed in accordance with the Quaid-i-Azam University, Islamabad regulations governing care and use of Laboratory animals and conformed to the ethical guidelines for the study of experimental pain in conscious animals established by the International Association for the Study of Pain. The current study was permitted by Bioethical Committee of Quaid-i-Azam University, Islamabad (Permit No: BEC-FBS-QAU2018-125).

Peripheral neuropathic pain was induced in mice by PSNL as previously described [16]. Briefly, mice were deeply anesthetized with ketamine $(100 \mathrm{mg} / \mathrm{kg}$ i.p.), the left sciatic nerve was exposed after the incision of skin and the exposed skin was swabbed with a povidone iodine topical $10 \% \mathrm{w} / \mathrm{v}$ solution. The sciatic nerve was freed of the adhering tissue gently for about $7 \mathrm{~mm}$, and four ligatures 
(chromic catgut 4.0) were loosely tied around approximately $1 / 3$ and $1 / 2$ diameter of the sciatic nerve. After performing partial nerve ligation, muscle and skin layer were at once sutured with thread, and topical antibiotic was applied. In sham-operated mice, an identical operation was performed, except that the sciatic nerve was not ligated. All surgical procedures were conducted under normal sterile conditions.

\subsection{Drug treatment and PSNL model}

Mice were randomly divided into 6 groups ( $n=10 /$ group). The sample size was selected according to the previously established protocol [40]. Optimal administration doses were selected according to the results of the preliminary experiments. ECN (1 and $10 \mathrm{mg} / \mathrm{kg}$ ) was administered i.p. to neuropathic mice once a day for 11 days, starting from the third day after surgery (Figure 18). Positive control (pregabalin $5 \mathrm{mg} / \mathrm{kg}$ ) was also administered i.p. to neuropathic mice once a day for 11 days, starting from the third day after surgery. No treatment was given to normal, sham and PSNL control groups. 3 to 4 mice from each group were sacrificed on day 7, 10 and 14 after PSNL surgery for biochemical evaluations (Figure 18).

Group 1: Normal (naïve mice; did not undergo any surgical procedure)

Group 2: Sham control (sciatic nerve exposure without nerve ligation)

Group 3: PSNL control (sciatic nerve exposure with nerve ligation)

Group 4: PSNL+pregabalin (5 mg/kg) (sciatic exposure with nerve ligation and pregabalin (5 $\mathrm{mg} / \mathrm{kg}$ ) administered)

Group 5: PSNL+ECN (1 mg/kg) (sciatic exposure with nerve ligation and ECN (1 mg/kg) administered)

Group 6: PSNL+ECN (10 mg/kg) (sciatic exposure with nerve ligation and ECN (10 mg/kg) administered)

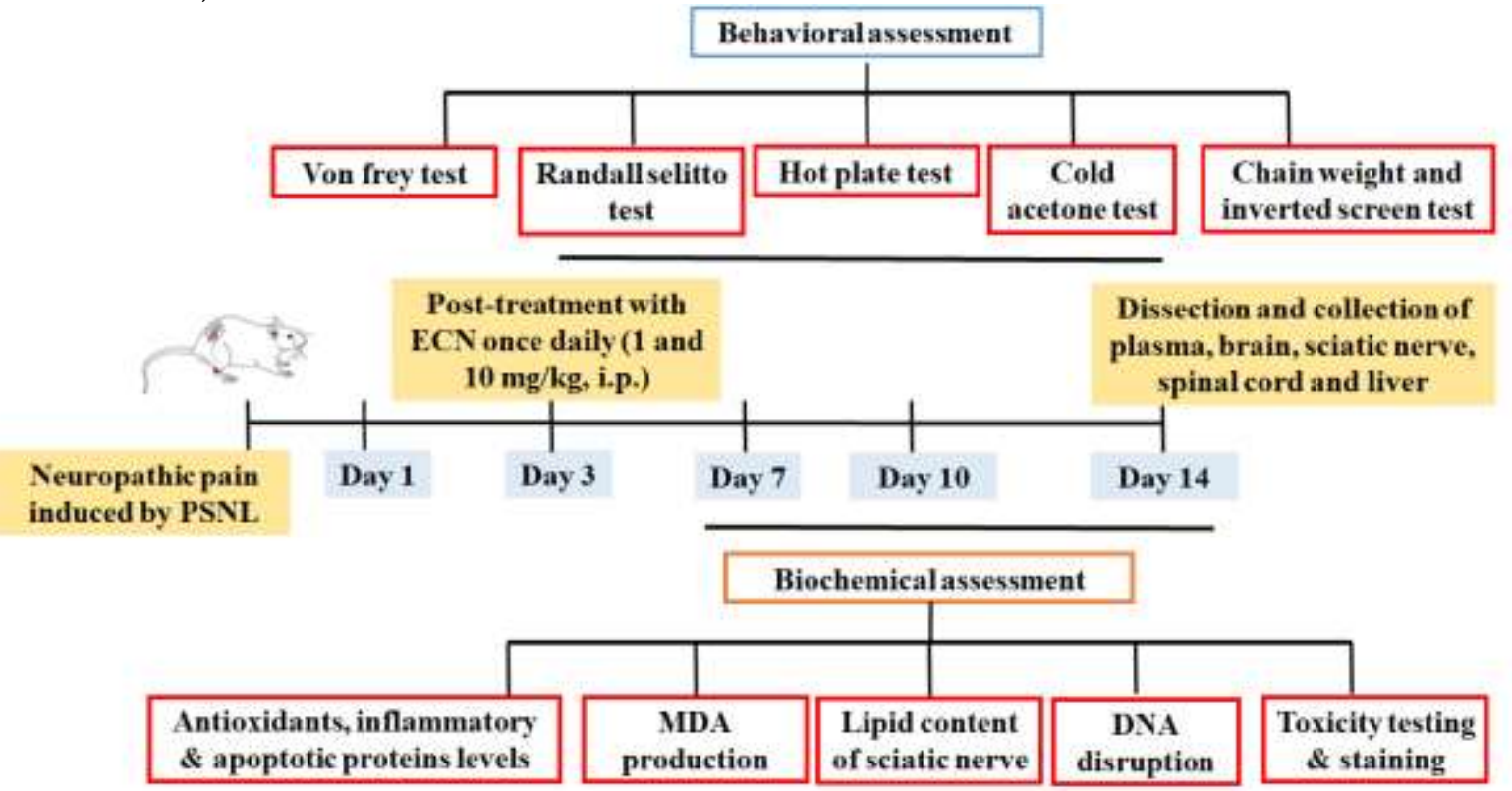

Figure 18. Experimental design for investigating the effect of ECN (1 and $10 \mathrm{mg} / \mathrm{kg}$ ) against PSNL neuropathic pain.

\subsection{Behavioural experiments}

The experimental animals were subjected for various behavioural studies for investigation of mechanical hyperalgesia, thermal hyperalgesia, mechanical allodynia, cold allodynia and muscle coordination carried out on the different time intervals of 1 day before PSNL surgery and 3, 7, 10 and 14 days post PSNL surgery. 


\subsubsection{Distress symptoms and survival rate}

The number of mice surviving in each group and mortality rates were recorded daily as previously described [41, 42]. Animals were observed throughout the experiment to record distress symptoms. Distress symptoms included general health, changes in temperament, gait weakness and reluctance to move. Scoring was carried out according to criteria mentioned previously [41]. The number of mice surviving in each group and mortality rates were recorded daily.

\subsubsection{Mechanical hyperalgesia}

In order to monitor the mechanical hyperalgesia, Randall Sellito (IITC Life Science Inc. CA, USA) was used as per method previously described with slight modifications [43, 44]. Before the start of the test, the mice were placed in a quiet room for 15-30 min to acclimatise with the environment. This test consists of evoking a hind paw flexion reflex with a hand hold force transducer and the force exerted is noted on the screen. The tip of the Randall Sellito was applied perpendicular to the plantar surface of the ipsilateral left hind paw and the pressure was increased gradually. The final reading of the Randall Sellito is the characteristic withdrawal of the paw and clear movement of the mice. The duration of paw withdrawal (PWD) was recorded with a cut-off latency of $15 \mathrm{~s}$ [45]. Mechanical hyperalgesia was evaluated before and after the initiation of the treatment. Three consecutive readings were taken for statistical analysis. Test was performed 1 day before PSNL surgery and 3, 7 , 10 and 14 days post PSNL surgery.

\subsubsection{Thermal hyperalgesia}

Thermal hyperalgesia of the plantar surface of the ipsilateral left hind paw was assessed as described previously $[46,47]$. The temperature of the hot plate was kept at $50 \pm 0.5^{\circ} \mathrm{C}$. Once the animals were placed on the top of preheated hot plate, the paw licking was taken as a positive response. The paw withdrawal latency (PWL) and PWD were recorded with a cut-off latency of $35 \mathrm{~s}$. Thermal hyperalgesia was evaluated before and after the initiation of the treatment. Three consecutive readings were taken for statistical analysis. Test was performed 1 day before PSNL surgery and 3, 7, 10 and 14 days post PSNL surgery.

\subsubsection{Mechanical allodynia}

In order to monitor the mechanical allodynia, a series of 9 von Frey filaments $(0.4,0.6,1,1.4,1.8$, 2, 4, 6 and $8 \mathrm{~g}$ ) were used as per method previously described with slight modifications [48, 49]. The filaments were applied to the plantar surface of the ipsilateral left hind paw and the applied force was increased gradually. Lifting or licking the paw was considered as a withdrawal response and the time taken to show a withdrawal response (PWL) three out of five times was considered positive. A cut-off latency of $15 \mathrm{~s}$ was imposed [45]. Three consecutive readings were taken for statistical analysis. Test was performed 1 day before PSNL surgery and 3, 7, 10 and 14 days post PSNL surgery.

\subsubsection{Cold allodynia}

In order to assess cold allodynia, acetone drop method was employed as per method previously described with slight modifications [50,51]. A $25 \mu$ l volume of acetone was sprayed onto the midplantar surface of the ipsilateral left hind paw, using a blunt needle connected to a syringe without touching the paw. The duration of the withdrawal response (PWD) during $60 \mathrm{~s}$ of the acetone application to the plantar surface of the ipsilateral left hind paw was recorded. Three consecutive readings were taken for statistical analysis. Test was performed 1 day before PSNL surgery and 3, 7 , 10 and 14 days post PSNL surgery.

4.5.6. Muscle coordination and motor coordination 
In order to determine the sedative effect of ECN on muscle strength and motor co-ordination, Kodzeila's inverted screen was performed as described previously [52, 53]. Each mouse was placed in the center of wire mesh screen and screen was inverted over $2 \mathrm{~s}$, with a mouse's head declining first. Investigator was trained to hold the screen steadily $40-50 \mathrm{~cm}$ above a padded surface. Time was recorded using digital stop watch when the mouse fall off and score was assigned according to the protocol [54]. A cut-off latency of $60 \mathrm{~s}$ was imposed [55]. Three consecutive readings were taken for statistical analysis. Test was performed 1 day before PSNL surgery and 3, 7, 10 and 14 days post PSNL surgery.

For full assessment of motor deficit, weight lifting test was performed as described previously [56]. Each weight was prepared using a thin wire mesh to which a length of steel chain consisting of from 1 to 7 links, each weighing $13 \mathrm{~g}$, was attached. Each mouse was held by the tail and successively allowed to grasp a series of increasing weights, with a rest of $10 \mathrm{~s}$ between each lift. A hold of $3 \mathrm{~s}$ is the criterion. Time was recorded using digital stop watch when the mice dropped the weight in less than $3 \mathrm{~s}$. If it held the weight for $3 \mathrm{~s}$ then it was allowed to grasp the next heavier weight. Score was assigned to each mouse. Three consecutive readings were taken for statistical analysis. Test was performed 1 day before PSNL surgery and 3, 7, 10 and 14 days post PSNL surgery.

\subsection{Biochemical experiments}

\subsubsection{Comet assay}

DNA damage in sciatic nerve and spinal cord tissues were assessed following 14 days post PSNL surgery by comet assay as described previously $[38,57,58]$. Small piece of sciatic nerve and spinal cord collected from mice after sacrifice were suspended separately in $1 \mathrm{ml}$ of cold lysing solution i.e., $\mathrm{Ca}^{2+}$ and $\mathrm{Mg}^{2+}$ free Hanks' balanced salt solution (HBSS) in a micro centrifuge tube and then the tissues were homogenized separately. About $5-10 \mu \mathrm{l}$ of the cell suspension was mixed in $0.5 \%$ low melting point agarose (LMPA), layered on the slides precoated with $1 \%$ normal agarose solution (NMA) and then covered with cover slip, retained for a duration of $10 \mathrm{~min}$ on an ice pack. After repeating this step twice, the slides were placed in lysing solution for $2 \mathrm{~h}$ at $4{ }^{\circ} \mathrm{C}$. After electrophoresis slides were stained with $1 \%$ ethidium bromide and were examined under fluorescent microscope. The amount of DNA damage was analysed by CASP 1.2.3.b software. The tail length and \% DNA in the tail was used to assess the amount of DNA damage.

\subsubsection{Histopathological analysis}

The Hematoxylin and Eosin (H\&E) staining of sciatic nerve, lumbar spinal cord and brain tissues were performed following 7 and 14 days post PSNL surgery. The collected sciatic nerve, lumbar spinal cord and brain were fixed with $10 \%$ formalin solution, mounted in paraffin blocks, cut into 4 $\mu \mathrm{m}$ sections and observed under microscope (100X).

\subsubsection{Quantitative real-time reverse transcriptase polymerase chain reaction}

The quantitative RT-PCR was used to determine the effect of ECN $(10 \mathrm{mg} / \mathrm{kg})$ on the mRNA expression levels of inflammatory mediators (COX-2, iNOS, TNF $\alpha$, IL-1 $\beta$ and IL-6) and anti-oxidant proteins (Nrf2, HO-1 and NQO1) following 7 and 14 days post PSNL surgery. Trizol Reagent was used to isolate the total RNA from the sciatic nerve and lumbar dorsal spinal cord (L4-L6) tissue of mice as described previously [46, 59, 60]. Briefly, GenDEPOT 0.2mL 8-strip tubes were used for quantitative PCR. 10ul each of forward primer and reverse primer along with 80ul DEPC-treated water (Sigma-Aldrich) and the fluorescent dye, SYBR green working solution was used. The reaction conditions were as follows $95^{\circ} \mathrm{C}$ for $5 \mathrm{~min}$ followed by 40 cycles at $95^{\circ} \mathrm{C}$ for $1 \mathrm{~min}$ (denaturation), then $55^{\circ} \mathrm{C}$ for $45 \mathrm{~s}$, and lastly $72^{\circ} \mathrm{C}$ for $30 \mathrm{~s}$ (annealing and elongation). The optimal conditions, melting point, and the reaction specificity were determined beforehand. 7300 real-time PCR system software was used for analysis. Beta actin, a housekeeping gene, was chosen as an internal standard. 


\subsubsection{Determination of malondialdehyde (MDA)}

To investigate the effect of ECN (10 mg/kg. i.p.) on oxidative stress marker, MDA level was quantified in sciatic nerve, lumbar dorsal spinal cord (L4-L6), hippocampus and prefrontal cortex tissues of day 7, 10 and 14 post PSNL surgery as described previously [61, 62]. The concentration of MDA, a marker of lipid peroxidation was analysed in the form of thiobarbituric acid reacting proteins (TBARS).

\subsubsection{Determination of nitric oxide (NO)}

NO level in sciatic nerve, lumbar dorsal spinal cord (L4-L6), hippocampus and prefrontal cortex tissues of day 7, 10 and 14 post PSNL surgery were determined by Griess assay according to the method previously described [46, 63]. The concentration of NO was determined by using Griess reagent, $1 \%$ sulfanilamide and $2.5 \%$ phosphoric acid. The concentration of nitrite was determined by measuring absorbance at $540 \mathrm{~nm}$.

\subsubsection{Determination of superoxide dismutase (SOD)}

To investigate the effect of ECN (10 mg/kg. i.p.) on anti-oxidant marker, SOD level was quantified in sciatic nerve, lumbar dorsal spinal cord (L4-L6), hippocampus and prefrontal cortex tissues of day 7, 10 and 14 post PSNL surgery according to the method previously described [33]. The SOD activity was measured by taking Tris-EDTA buffer (50 Mm, pH 8.5), pyrogallol (24 mM) and 10 $\mu \mathrm{l}$ of sample in a total volume of $0.2 \mathrm{ml}$. The final readings were noted in triplicate at $420 \mathrm{~nm}$.

\subsubsection{Determination of glutathione (GSH)}

GSH level was quantified in sciatic nerve, lumbar dorsal spinal cord (L4-L6), hippocampus and prefrontal cortex tissues of day 7, 10 and 14 post PSNL surgery as described previously [38]. The reduced glutathione level was measured by mixing $0.1 \mathrm{ml}$ of tissue homogenate obtained from each dilution and $2.4 \mathrm{ml}$ from phosphate buffer solution. The final volume was adjusted to $3 \mathrm{ml}$ by adding $0.5 \mathrm{ml}$ DTNB solution. The absorbance was measured at $412 \mathrm{~nm}$.

\subsubsection{Determination of GST}

GST level was quantified in sciatic nerve, lumbar dorsal spinal cord (L4-L6), hippocampus and prefrontal cortex tissues of day 7, 10 and 14 post PSNL surgery as described previously [43]. The enzyme was quantified by its ability to conjugate GSH and CDNB. The level of GST was determined by mixing $0.1 \mathrm{ml}$ of homogenate and $0.1 \mathrm{ml}$ of CDNB. Finally $0.1 \mathrm{M}$ phosphate (pH 6.5) buffer was added to make the final volume up to $3 \mathrm{ml}$. The absorbance was measured at $314 \mathrm{~nm}$.

\subsubsection{Determination of catalase (CAT)}

Catalase level was quantitated in sciatic nerve, lumbar dorsal spinal cord (L4-L6), hippocampus and prefrontal cortex tissues of day 7, 10 and 14 post PSNL surgery according to previously described methodology [61]. The catalase activity was determined by taking $3 \mathrm{ml}$ of $\mathrm{H}_{2} \mathrm{O}_{2}$-phospahte buffer in an experimental cuvette and by the rapid addition of $40 \mu \mathrm{l}$ of an enzyme extract. The final readings were noted in triplicate at $240 \mathrm{~nm}$.

\subsubsection{Analysis of renal and hepatotoxicity}

The systemic toxicity of ECN (10 mg/kg, i.p) in blood was assessed by measuring the levels of alanine amino transferase (AST), aspartate amino transferase (ALT) and creatinine. The whole blood obtained on 14 days after PSNL surgery was centrifuged at $5000 \mathrm{rpm}$ for $5 \mathrm{~min}$ to separate the serum from blood cells and the temperature was maintained at $4^{\circ} \mathrm{C}$. The serum was used to determine the level of ALT, AST and creatinine. 


\subsubsection{Immunohistochemistry}

Immunohistochemical analysis of Nrf2 and caspase-3 were performed following 14 days post PSNL surgery according to the method already mentioned [61]. Briefly, lumbar dorsal spinal cord (L4-L6) tissues (paraffin-fixed) were deparaffinised and rehydrated through xylene and alcohol. The intracellular peroxidase was quenched by $\mathrm{H}_{2} \mathrm{O}_{2}(3 \%)$ in menthol and then incubated for 20 min with goat serum. The slides were incubated overnight long with the mouse anti-Nrf2 and mouse anticaspase 3 antibodies. After washing, the slides were incubated in biotinylated goat-anti-mouse secondary antibodies, then incubated with $A B C$ reagents for $1 \mathrm{~h}$. Further washed with phosphate buffer saline and stained with diaminobenzidine solution. Images were taken under light microscope. The relative expression of Nrf2 and caspase-3 proteins were measured using Image tool.

\subsubsection{Determination of sciatic nerve structural damage}

The sciatic nerves were purged and placed at $-80^{\circ} \mathrm{C}$ on day 14 after PSNL for the spectroscopic analysis to check lipid content of myelin sheath in PSNL model. The samples were lyophilized and were used directly in the Fourier transform infrared (FTIR) spectrometer [64]. Moreover, the instrument was constantly removed from dry air to dismiss water vapours. The infrared spectra of sciatic nerve specimens were acquired in the FTIR spectrometer IR tracer (Shimadzu, Japan). The specimens were subjected to the range of 650 to $4000 \mathrm{~cm}^{-1}$ with a resolving power of $4 \mathrm{~cm}^{-1}$. Essential FTIR was used for digital data manipulation. For the estimation of position of bands, the wavenumber values coinciding with the mid of weight were utilized.

\subsubsection{Statistical analysis}

Results were expressed as mean \pm standard deviation (S.D). Sigma plot version 12.5 (statistical software) was used for the statistical analysis. Two-way analysis of variance (ANOVA) was applied following Dunnett's t-tests for the assessment of statistical significance amongst various treated groups. For the statistical significance the value of "P" less than 0.05 was selected as criterion of significance difference.

\section{Conclusions}

The present work suggests that ECN could treat PSNL-induced neuropathic pain through alleviation of distress symptoms, biochemical alteration in sciatic nerve morphology and modulation of expression of anti-oxidant proteins, pro-apoptotic proteins and pro-inflammatory cytokines represented in Figure 19. Unlike opioids and nonsteroidal anti-inflammatory drugs, minimal side effects and improved safety profile of ECN might contribute towards attenuating pathological condition of neuropathic pain. Thus, on the basis of present findings, it is concluded that ECN could be used in the treatment of PSNL induced peripheral neuropathy. 


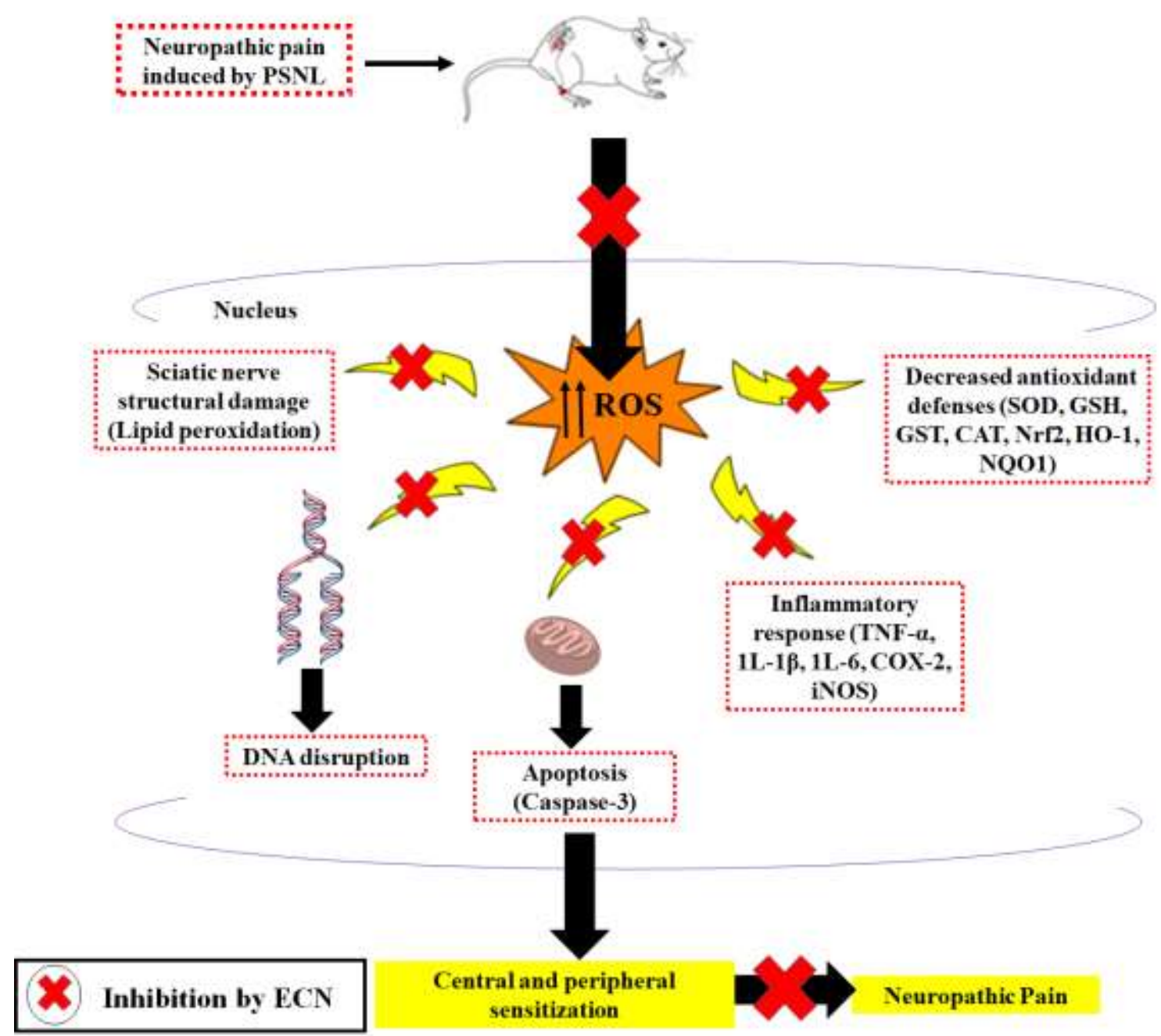

Figure 19. Proposed mechanism of anti-neuropathic effect of ECN in PSNL model.

Acknowledgments: This work was supported by the Higher Education Commission (HEC), Pakistan under the SRGP funding (No. 357 SRGP/HEC/2014). The funding body provided necessary financial support from design to the completion of the study (including collection, analysis, interpretation and presentation of data). The authors are grateful to Prof. Yeong Shik Kim, Seoul National University, South Korea for providing the natural compound, 7 $\beta$-(3-ethyl-cis-crotonoyloxy)-1 $\alpha$-(2-methylbutyryloxy)-3,14-dehydro-Z notonipetranone.

Author Contributions: Conceptualization, A.K., and S.K.; methodology, A.K., S.K., A.K., and B.S.; software, A.K., and B.S.; validation, E.K., E.K.S., and S.K.; formal analysis, A.K., and B.K.; investigation, A.K., and B.S.; resources, S.K.; data curation, S.K.; writing - original draft preparation, A.K.; writing - review and editing, S.K.; visualization, E.K.S.; supervision, S.K.; project administration, S.K.; funding acquisition, S.K., and E.K.S.. All authors have read and approved the final manuscript.

Funding: This work was supported by the Higher Education Commission (HEC), Pakistan under the SRGP funding (No. 357 SRGP/HEC/2014). The funding body provided necessary financial support from design to the completion of the study (including collection, analysis, interpretation and presentation of data).

Conflicts of Interest: The authors declare that they have no conflicts of interest.

\section{References}

1. Alles, S. R.; Smith, P. A., Etiology and pharmacology of neuropathic pain. Pharmacological reviews 2018, 70, (2), 315-347.

2. Colloca, L.; Ludman, T.; Bouhassira, D.; Baron, R.; Dickenson, A. H.; Yarnitsky, D.; Freeman, R.; Truini, A.; Attal, N.; Finnerup, N. B., Neuropathic pain. Nature reviews Disease primers 2017, 3, 17002. 
3. Khan, A.; Khan, S.; Kim, Y. S., Insight into Pain Modulation: Nociceptors Sensitization and Therapeutic Targets. Current drug targets 2019, 20, (7), 775-788.

4. Brell, J. M., Animal models of peripheral neuropathy: modeling what we feel, understanding what they feel. ILAR journal 2014, 54, (3), 253-258.

5. Khan, S. M.; Kim, Y. S., Reviews: molecular mechanism of inflammatory signaling and predominant role of Saposhnikovia divaricata as anti-inflammatory potential. Natural Product Sciences 2013, 19, (2), 120-126.

6. Jaggi, A. S.; Jain, V.; Singh, N., Animal models of neuropathic pain. Fundamental $\mathcal{E}$ clinical pharmacology 2011, 25, (1), 1-28.

7. Boyce-Rustay, J. M.; Jarvis, M. F., Neuropathic pain: models and mechanisms. Current pharmaceutical design 2009, 15, (15), 1711-1716.

8. Colleoni, M.; Sacerdote, P., Murine models of human neuropathic pain. Biochimica et Biophysica Acta (BBA)Molecular Basis of Disease 2010, 1802, (10), 924-933.

9. Negi, G.; Kumar, A.; S Sharma, S., Nrf2 and NF- $\kappa B$ modulation by sulforaphane counteracts multiple manifestations of diabetic neuropathy in rats and high glucose-induced changes. Current neurovascular research 2011, 8, (4), 294-304.

10. Abbaszadeh, A.; Darabi, S.; Hasanvand, A.; Amini-Khoei, H.; Abbasnezhad, A.; Choghakhori, R.; Aaliehpour, A., Minocycline through attenuation of oxidative stress and inflammatory response reduces the neuropathic pain in a rat model of chronic constriction injury. Iranian journal of basic medical sciences 2018, 21, (2), 138.

11. Lee, J.-M.; Calkins, M. J.; Chan, K.; Kan, Y. W.; Johnson, J. A., Identification of the NF-E2-related factor-2dependent genes conferring protection against oxidative stress in primary cortical astrocytes using oligonucleotide microarray analysis. Journal of Biological Chemistry 2003, 278, (14), 12029-12038.

12. Rahbardar, M. G.; Amin, B.; Mehri, S.; Mirnajafi-Zadeh, S. J.; Hosseinzadeh, H., Rosmarinic acid attenuates development and existing pain in a rat model of neuropathic pain: an evidence of anti-oxidative and antiinflammatory effects. Phytomedicine 2018, 40, 59-67.

13. Clark, A. K.; Old, E. A.; Malcangio, M., Neuropathic pain and cytokines: current perspectives. Journal of pain research 2013, 6, 803 .

14. Khan, A.; Khan, S.; Ali, H.; Shah, K. U.; Ali, H.; Shehzad, O.; Onder, A.; Kim, Y. S., Anomalin attenuates LPS-induced acute lungs injury through inhibition of AP-1 signaling. International immunopharmacology 2019, 73, 451-460.

15. Lee, J.; Song, K.; Huh, E.; Oh, M. S.; Kim, Y. S., Neuroprotection against 6-OHDA toxicity in PC12 cells and mice through the Nrf2 pathway by a sesquiterpenoid from Tussilago farfara. Redox biology 2018, 18, 6-15.

16. Valsecchi, A. E.; Franchi, S.; Panerai, A. E.; Sacerdote, P.; Trovato, A. E.; Colleoni, M., Genistein, a natural phytoestrogen from soy, relieves neuropathic pain following chronic constriction sciatic nerve injury in mice: anti-inflammatory and antioxidant activity. Journal of neurochemistry 2008, 107, (1), 230-240.

17. Severcan, F.; Sahin, I.; Kazanc1, N., Melatonin strongly interacts with zwitterionic model membranesevidence from Fourier transform infrared spectroscopy and differential scanning calorimetry. Biochimica et Biophysica Acta (BBA)-Biomembranes 2005, 1668, (2), 215-222.

18. Mantsch, H. H., Biological applications of Fourier transform infrared spectroscopy: a study of phase transitions in biomembranes. Journal of Molecular Structure 1984, 113, $201-212$.

19. Severcan, F.; Toyran, N.; Kaptan, N.; Turan, B., Fourier transform infrared study of the effect of diabetes on rat liver and heart tissues in the $\mathrm{CH}$ region. Talanta 2000, 53, (1), 55-59.

20. Severcan, F.; Kaptan, N.; Turan, B., Fourier transform infrared spectroscopic studies of diabetic rat heart crude membranes. Spectroscopy 2003, 17, (2, 3), 569-577.

21. Severcan, F., Vitamin E decreases the order of the phospholipid model membranes in the gel phase: an FTIR study. Bioscience reports 1997, 17, (2), 231-235.

22. Dworkin, R. H.; Backonja, M.; Rowbotham, M. C.; Allen, R. R.; Argoff, C. R.; Bennett, G. J.; Bushnell, M. C.; Farrar, J. T.; Galer, B. S.; Haythornthwaite, J. A., Advances in neuropathic pain: diagnosis, mechanisms, and treatment recommendations. Archives of neurology 2003, 60, (11), 1524-1534.

23. Woolf, C. J.; Mannion, R. J., Neuropathic pain: aetiology, symptoms, mechanisms, and management. The lancet 1999, 353, (9168), 1959-1964.

24. Khan, S.; Shehzad, A.; Shehzad, O.; Al-Suhaimi, E. A., Inpatient antibiotics pharmacology and physiological use in Hayatabad medical complex, Pakistan. International journal of physiology, pathophysiology and pharmacology 2013, 5, (2), 120.

25. Aswar, M.; Patil, V., Ferulic acid ameliorates chronic constriction injury induced painful neuropathy in rats. Inflammopharmacology 2016, 24, (4), 181-188.

26. Zhao, W. X.; Wang, P. F.; Song, H. G.; Sun, N., Diosgenin attenuates neuropathic pain in a rat model of chronic constriction injury. Molecular medicine reports 2017, 16, (2), 1559-1564. 
27. Khan, S.; Choi, R. J.; Shehzad, O.; Kim, H. P.; Islam, M. N.; Choi, J. S.; Kim, Y. S., Molecular mechanism of capillarisin-mediated inhibition of MyD88/TIRAP inflammatory signaling in in vitro and in vivo experimental models. Journal of ethnopharmacology 2013, 145, (2), 626-637.

28. Joseph, E. K.; Levine, J. D., Caspase signalling in neuropathic and inflammatory pain in the rat. European Journal of Neuroscience 2004, 20, (11), 2896-2902.

29. Khan, S.; Choi, R. J.; Lee, J.; Kim, Y. S., Attenuation of neuropathic pain and neuroinflammatory responses by a pyranocoumarin derivative, anomalin in animal and cellular models. European journal of pharmacology 2016, 774, 95-104.

30. Olmos, G.; Lladó, J., Tumor necrosis factor alpha: a link between neuroinflammation and excitotoxicity. Mediators of inflammation 2014, 2014.

31. Cao, H.; Zhang, Y.-Q., Spinal glial activation contributes to pathological pain states. Neuroscience $\mathcal{E}$ Biobehavioral Reviews 2008, 32, (5), 972-983.

32. Scheid, T.; Moraes, M. S.; Henriques, T. P.; Riffel, A. P. K.; Belló-Klein, A.; Poser, G. L. V.; Ethur, E. M.; Partata, W. A., Effects of Methanol Fraction from Leaves of Schinus terebinthifolius Raddi on Nociception and Spinal-Cord Oxidative Biomarkers in Rats with Neuropathic Pain. Evidence-Based Complementary and Alternative Medicine 2018, 2018.

33. Moulahoum, H.; Boumaza, B. M. A.; Ferrat, M.; Nagy, A.-L.; Olteanu, D. E.; Bounaama, A.; Clichici, S., Aberrant crypt foci are regionally affected by zinc treatment in a 1, 2-dimethylhydrazine induced colon carcinogenesis model. Journal of Trace Elements in Medicine and Biology 2018, 47, 21-30.

34. Nazıroğlu, M.; Dikici, D. M.; Dursun, Ş., Role of oxidative stress and Ca 2+ signaling on molecular pathways of neuropathic pain in diabetes: focus on TRP channels. Neurochemical research 2012, 37, (10), 2065-2075.

35. Chinnaiyan, A. M.; Orth, K.; O'Rourke, K.; Duan, H.; Poirier, G. G.; Dixit, V. M., Molecular Ordering of the Cell Death Pathway Bcl-2 AND Bcl-x function upstream of the CED-3-like apoptotic proteases. Journal of Biological Chemistry 1996, 271, (9), 4573-4576.

36. Maione, S.; Siniscalco, D.; Galderisi, U.; de Novellis, V.; Uliano, R.; Di Bernardo, G.; Berrino, L.; Cascino, A.; Rossi, F., Apoptotic genes expression in the lumbar dorsal horn in a model neuropathic pain in rat. Neuroreport 2002, 13, (1), 101-106.

37. Wu, F.; Miao, X.; Chen, J.; Sun, Y.; Liu, Z.; Tao, Y.; Yu, W., Down-regulation of GAP-43 by inhibition of caspases3 in a rat model of neuropathic pain. International journal of clinical and experimental pathology 2012, 5, (9), 948.

38. Shal, B.; Khan, A.; Naveed, M.; Khan, N. U.; AlSharari, S. D.; Kim, Y. S.; Khan, S., Effect of 25-methoxy hispidol A isolated from Poncirus trifoliate against bacteria-induced anxiety and depression by targeting neuroinflammation, oxidative stress and apoptosis in mice. Biomedicine $\mathcal{E}$ Pharmacotherapy 2019, 111, 209-223.

39. Song, K.; Lee, K. J.; Kim, Y. S., Development of an efficient fractionation method for the preparative separation of sesquiterpenoids from Tussilago farfara by counter-current chromatography. Journal of Chromatography A 2017, 1489, 107-114.

40. Charan, J.; Biswas, T., How to calculate sample size for different study designs in medical research? Indian journal of psychological medicine 2013, 35, (2), 121.

41. Atiq, A.; Shal, B.; Naveed, M.; Khan, A.; Ali, J.; Zeeshan, S.; Al-Sharari, S. D.; Kim, Y. S.; Khan, S., Diadzein ameliorates 5 -fluorouracil-induced intestinal mucositis by suppressing oxidative stress and inflammatory mediators in rodents. European journal of pharmacology 2019, 843, 292-306.

42. Ullah, H.; Khan, A.; Baig, M. W.; Ullah, N.; Ahmed, N.; Tipu, M. K.; Ali, H.; Khan, S., Poncirin attenuates CCL4-induced liver injury through inhibition of oxidative stress and inflammatory cytokines in mice. BMC Complementary Medicine and Therapies 2020, 20, 1-14.

43. Naveed, M.; Khan, S. Z.; Zeeshan, S.; Khan, A.; Shal, B.; Atiq, A.; Ali, H.; Ullah, R.; Khan, S., A new cationic palladium (II) dithiocarbamate exhibits anti-inflammatory, analgesic, and antipyretic activities through inhibition of inflammatory mediators in in vivo models. Naunyn-Schmiedeberg's archives of pharmacology 2019, 1-17.

44. Khan, S. M.; Choi, R. J.; Lee, D. U.; Kim, Y. S., Sesquiterpene derivatives isolated from Cyperus rotundus L. inhibit inflammatory signaling mediated by NF-кB. Natural Product Sciences 2011, 17, (3), 250-255.

45. Shahid, M.; Subhan, F.; Ahmad, N.; Ali, G.; Akbar, S.; Fawad, K.; Sewell, R. D. E., Topical gabapentin gel alleviates allodynia and hyperalgesia in the chronic sciatic nerve constriction injury neuropathic pain model. European Journal of Pain 2017, 21, (4), 668-680.

46. Khan, A.; Ullah, M. Z.; Afridi, R.; Rasheed, H.; Khalid, S.; Ullah, H.; Ali, H.; AlSharari, S. D.; Kim, Y. S.; Khan, S., Antinociceptive properties of 25-methoxy hispidol A, a triterpinoid isolated from Poncirus trifoliata (Rutaceae) through inhibition of NF- $\kappa$ B signalling in mice. Phytotherapy research 2019, 33, (2), 327-341.

47. Khalid, S.; Khan, A.; Shal, B.; Ali, H.; Kim, Y. S.; Khan, S., Suppression of TRPV1 and P2Y nociceptors by honokiol isolated from Magnolia officinalis in 3rd degree burn mice by inhibiting inflammatory mediators. Biomedicine \& Pharmacotherapy 2019, 114, 108777. 
48. Khalid, S.; Ullah, M. Z.; Khan, A. U.; Afridi, R.; Rasheed, H.; Khan, A.; Ali, H.; Kim, Y. S.; Khan, S., Antihyperalgesic properties of honokiol in inflammatory pain models by targeting of NF- $\kappa B$ and Nrf2 signaling. Frontiers in pharmacology 2018, 9, 140.

49. Khan, S.; Shehzad, O.; Chun, J.; Kim, Y. S., Mechanism underlying anti-hyperalgesic and anti-allodynic properties of anomalin in both acute and chronic inflammatory pain models in mice through inhibition of NF- $\kappa B$, MAPKs and CREB signaling cascades. European journal of pharmacology 2013, 718, (1-3), 448-458.

50. Zhou, J.; Wang, L.; Wang, J.; Wang, C.; Yang, Z.; Wang, C.; Zhu, Y.; Zhang, J., Paeoniflorin and albiflorin attenuate neuropathic pain via mapk pathway in chronic constriction injury rats. Evidence-Based Complementary and Alternative Medicine 2016, 2016.

51. Khan, S.; Shehzad, O.; Chun, J.; Choi, R. J.; Park, S.; Islam, M. N.; Choi, J. S.; Kim, Y. S., Anti-hyperalgesic and anti-allodynic activities of capillarisin via suppression of inflammatory signaling in animal model. Journal of ethnopharmacology 2014, 152, (3), 478-486.

52. Rasheed, H.; Afridi, R.; Khan, A. U.; Ullah, M. Z.; Khalid, S.; Atiq, A.; Kashif, H.; Ahmed, M. N.; Kim, Y. S.; Khan, S., Anti-inflammatory, anti-rheumatic and analgesic activities of 2-(5-mercapto-1, 3, 4-oxadiazol-2yl)-N-propylbenzenesulphonamide (MOPBS) in rodents. Inflammopharmacology 2018, 26, (4), 1037-1049.

53. Afridi, R.; Khan, A. U.; Khalid, S.; Shal, B.; Rasheed, H.; Ullah, M. Z.; Shehzad, O.; Kim, Y. S.; Khan, S., Antihyperalgesic properties of a flavanone derivative Poncirin in acute and chronic inflammatory pain models in mice. BMC Pharmacology and Toxicology 2019, 20, (1), 1-16.

54. Contet, C.; Rawlins, J. N. P.; Deacon, R. M., A comparison of 129S2/SvHsd and C57BL/6JOlaHsd mice on a test battery assessing sensorimotor, affective and cognitive behaviours: implications for the study of genetically modified mice. Behavioural brain research 2001, 124, (1), 33-46.

55. Rasheed, H.; Afridi, R.; Khan, A. U.; Ullah, M. Z.; Khalid, S.; Atiq, A.; Kashif, H.; Ahmed, M. N.; Kim, Y. S.; Khan, S., Anti-inflammatory, anti-rheumatic and analgesic activities of 2-(5-mercapto-1, 3, 4-oxadiazol-2yl)-N-propylbenzenesulphonamide (MOPBS) in rodents. Inflammopharmacology 2018, 1-13.

56. Deacon, R. M.; Croucher, A.; Rawlins, J. N. P., Hippocampal cytotoxic lesion effects on species-typical behaviours in mice. Behavioural brain research 2002, 132, (2), 203-213.

57. Shal, B.; Khan, A.; Naveed, M.; Ali, H.; Seo, E. K.; Choi, H.; Khan, S., Neuroprotective effect of 25Methoxyhispidol A against CCl4-induced behavioral alterations by targeting VEGF/BDNF and caspase-3 in mice. Life Sciences 2020, 117684.

58. Khan, A.; Shal, B.; Naveed, M.; Nasir, B.; Irshad, N.; Ali, H.; Khan, S., Matrine alleviates neurobehavioral alterations via modulation of JNK-mediated caspase-3 and BDNF/VEGF signaling in a mouse model of burn injury. Psychopharmacology 2020.

59. Khan, S.; Shin, E. M.; Choi, R. J.; Jung, Y. H.; Kim, J.; Tosun, A.; Kim, Y. S., Suppression of LPS-induced inflammatory and NF- $\kappa$ B responses by anomalin in RAW 264.7 macrophages. Journal of Cellular Biochemistry 2011, 112, (8), 2179-2188.

60. Khan, S.; Shehzad, O.; Cheng, M.-S.; Li, R.-J.; Kim, Y. S., Pharmacological mechanism underlying antiinflammatory properties of two structurally divergent coumarins through the inhibition of proinflammatory enzymes and cytokines. Journal of Inflammation 2015, 12, (1), 47.

61. Khan, A.; Shal, B.; Naveed, M.; Shah, F. A.; Atiq, A.; Khan, N. U.; Kim, Y. S.; Khan, S., Matrine ameliorates anxiety and depression-like behaviour by targeting hyperammonemia-induced neuroinflammation and oxidative stress in CCl4 model of liver injury. Neurotoxicology 2019, 72, 38-50.

62. Khan, S.; Shehzad, O.; Lee, K. J.; Tosun, A.; Kim, Y. S., Anti-inflammatory properties of samidin from Seseli resinosum through suppression of NF- $\mathrm{B}$ and AP-1-mediated-genes in LPS-stimulated RAW 264.7 cells. Archives of pharmacal research 2014, 37, (11), 1496-1503.

63. Khan, S.; Shehzad, O.; Jin, H.-G.; Woo, E.-R.; Kang, S. S.; Baek, S. W.; Kim, J.; Kim, Y. S., Anti-inflammatory mechanism of 15, 16-epoxy-3 $\alpha$-hydroxylabda-8, 13 (16), 14-trien-7-one via inhibition of LPS-induced multicellular signaling pathways. Journal of natural products 2012, 75, (1), 67-71.

64. Kazmi, Z.; Zeeshan, S.; Khan, A.; Malik, S.; Shehzad, A.; Seo, E. K.; Khan, S., Anti-epileptic activity of daidzin in PTZ-induced mice model by targeting oxidative stress and BDNF/VEGF signaling. NeuroToxicology 2020.

65. Ozek, N. S.; Sara, Y.; Onur, R.; Severcan, F., Low dose simvastatin induces compositional, structural and dynamic changes in rat skeletal extensor digitorum longus muscle tissue. Biosci. Rep 2010, 30, (1), 41-50.

66. Garip, S.; Severcan, F., Determination of simvastatin-induced changes in bone composition and structure by Fourier transform infrared spectroscopy in rat animal model. Journal of pharmaceutical and biomedical analysis $2010,52,(4), 580-588$. 